\title{
Nrf-2-driven long noncoding RNA ODRUL contributes to modulating silver nanoparticle-induced effects on erythroid cells
}

\author{
Ming Gao ${ }^{\mathrm{a}, 1}$, Beibei Zhao ${ }^{\mathrm{b}, 1}$, Minjun Chen ${ }^{\mathrm{c}}$, Yun Liu ${ }^{\mathrm{a}, \mathrm{d}}$, Ming Xu ${ }^{\mathrm{a}}$, Zhe Wang ${ }^{\mathrm{e}}$, \\ Sijin Liu ${ }^{\text {a, * }}$, Chengdong Zhang ${ }^{\text {b, *** }}$ \\ a State Key Laboratory of Environmental Chemistry and Ecotoxicology, Research Center for Eco-Environmental Sciences, Chinese Academy of Sciences, \\ Beijing 100085, China \\ ${ }^{\mathrm{b}}$ College of Environmental Science and Engineering, Ministry of Education Key Laboratory of Pollution Processes and Environmental Criteria, Tianjin Key \\ Laboratory of Environmental Remediation and Pollution Control, Nankai University, Tianjin, China \\ ${ }^{\mathrm{c}}$ College of Environment and Resource, Research Center of Environment and Health, Shanxi University, Taiyuan, Shanxi 030006, China \\ ${ }^{\mathrm{d}}$ Key Laboratory of Ion Beam Bioengineering, Hefei Institutes of Physical Science, Chinese Academy of Sciences and Anhui Province, Hefei, Anhui 230031, \\ China \\ e School of Public Health, Xinxiang Medical University, Xinxiang, Henan Province 453003, China
}

\section{A R T I C L E I N F O}

\section{Article history:}

Received 26 January 2017

Received in revised form

19 March 2017

Accepted 21 March 2017

Available online 22 March 2017

\section{Keywords:}

Silver nanoparticles

IncRNA

ODRUL

Cell death

Erythroid cells

\begin{abstract}
A B S T R A C T
The biosafety and biological effects of silver nanoparticles (AgNPs) on human health attract increasing concern. Although considerable studies have been performed to reveal the molecular mechanisms responsible for AgNP-induced effects, the current understanding mainly focuses on oxidative stressassociated signaling pathways activated by $\mathrm{Ag}$ particles and/or $\mathrm{Ag}$ ions. However, the molecular bases underlying the activation of these stress signaling pathways have not been thoroughly elucidated yet. In the current study, we aimed to shed light on the molecular bases of AgNP-induced effects on erythroid cells from the perspective of long noncoding RNAs. We identified a long-noncoding RNA molecule, ODRUL, which was substantially enhanced in K562 erythroid cells responding to AgNPs, coupled to accelerated cell death. Further, we uncovered oxidative stress-driven Nrf2 transcriptionally promoted ODRUL expression in K562 cells. Downstream of Nrf2-ODRUL activation by AgNPs, ODRUL was recognized to interact with PI4K $\alpha$ protein to modulate the activities of its targets AKT and JNK. As a result, the $\mathrm{Bcl}-2$ level was negatively regulated by PI4K-AKT/JNK signaling under AgNP-induced stress, leading to enhanced cell death. Together, our findings unearthed that Nrf2-mediated IncRNA ODRUL was indispensable for AgNP-induced toxicity in erythroid cells through regulation of AKT/JNK-Bcl-2 signaling dependent on a physical interaction with PI4K $\alpha$. Thus, this study would open a new path to depict the molecular bases of AgNP-induced effects on erythroid cells.
\end{abstract}

() 2017 Elsevier Ltd. All rights reserved.

\section{Introduction}

Increasing applications and usage of nanomaterials and

Abbreviations: AKT, protein kinase B (PKB); Bcl-2, B-cell lymphoma-2; CAT, Catalase; ERK, extracellular regulated protein kinases; HO-1, hemeoxygenase; JNK, c-Jun N-terminal kinase; LncRNA, long non-coding RNA; Nrf2, nuclear factor erythroid 2-related factor 2; ODRUL, osteosarcoma doxorubicin-resistance related up-regulated IncRNA; PI4K $\alpha$, phosphatidylinositol 4-kinase alpha; SOD, superoxide dismutase; STAT5, signal transducer and activator of transcription 5.

* Corresponding author.

** Corresponding author

E-mail addresses: sjliu@rcees.ac.cn (S. Liu), zhangchengdong@nankai.edu.cn (C. Zhang).

1 These authors equally contribute to this work. nanoproducts in a wide spectrum of fields would increase the potential risk to human health [1-3]. Among the nanomaterials, silver nanoparticles (AgNPs) represent the largest family of nanomaterials with the greatest applications thus far [4,5]. The toxicity and adverse impacts of AgNPs on human health have been greatly concerned. Numerous studies have documented that AgNPs incurred cytotoxicity to various cells by producing reactive oxygen species (ROS) and oxidative stress stemming from either Ag particles or Ag ions, leading to plasma membrane impairment, mitochondrial dysfunction, chromosomal abnormalities, DNA damage, and so on [6-8]. However, the detailed molecular bases underlying these AgNP-induced toxic events remain elusive. For example, the initiation of molecular signaling to trigger cell death has not been clearly elucidated. 
Of non-coding RNAs, long noncoding RNAs (lncRNAs) are novel transcripts with the length greater than 200 nucleotides, but without a protein-coding function [9-11]. Recent studies have demonstrated that IncRNAs are in fact crucial regulators for gene expression and protein functions for fine-tuned cellular homeostasis. LncRNAs contribute to the regulation of cell survival, differentiation, metabolism, DNA repair and other cellular processes under normal physiological settings and in response to diverse endogenous and exotic stresses [12-14]. LncRNAs modulate the expression of a large number of genes at the post-transcriptional level through diverse mechanisms, including interaction with functional mRNAs to alter mRNA stability and adsorption of microRNAs (miRNAs) like a sponge to regulate the latter's actions $[10,15,16]$. Moreover, IncRNAs are also verified to interact with proteins, such as polycomb repressive complex 2 (PRC2) components, in order to orchestrate protein stability and functions [17,18]. Down-regulated expression of IncRNAs has been found to cause the occurrence and progression of a large array of disorders including cancers [13,19]. Additionally, emerging evidence suggests that lncRNAs are also involved in the regulation of nanomaterialinduced toxicity [20,21]. For example, lncRNA XLOC 010623 and linc-37 were dysregulated in response to self-assembled tetrahedral DNA nanostructures (TDNs) and graphene oxide (GO), respectively $[20,21]$. These findings implied a potentially important role of lncRNAs in nanomaterial-induced biological effects; however, the molecular mechanisms are still unclear. To the best of our knowledge, there are no studies to investigate the toxicological signaling regulated by lncRNAs upon AgNPs.

Upon various exposure routes, nanomaterials are transported to distant organs with the aid of red blood cells (RBCs), and finally accumulate in liver, spleen, bone marrow and other organs [22,23]. Of these distant sites, bone marrow and spleen (only under stresses) are responsible for hematopoiesis including RBC formation [24]. Thus, RBCs and their progenitors are severely subjected to nanomaterial-induced stress during transportation, circulation and accumulation in erythropoietic sites. We recently demonstrated that AgNPs repressed RNA transcriptional activity through a direct reciprocal interaction with RNA polymerase in erythroid progenitor cells [25]. Furthermore, we reported that AgNPs inhibited globin transcription through reducing the methylation status of histone in erythroid progenitor cells, highlighting an important role of epigenetic mechanisms in nanotoxicity [26]. In the current study, we aimed to uncover the IncRNA-initiated signaling pathways in erythroid cells after AgNP exposure. Our combined results revealed that IncRNA ODRUL was a novel coordinator for AgNP-induced cytotoxicity in erythroid cells, which linked the Nrf2 stress signaling with the AKT/JNK-Bcl-2 survival signaling through its partner PI4K $\alpha$.

\section{Materials and methods}

\subsection{Nanoparticle characterization}

AgNPs coated with PVP were purchased from Cold stones company (Suzhou, China). AgNPs were characterized by transmission electron microscopy (TEM, Hitachi H-7500, Japan). Hydrodynamic diameter and zeta-potential were assayed using dynamic light scattering (DLS) (Malvern, U.K).

\subsection{Cell culture}

Human chronic myeloid leukemia cell line K562 was obtained from the Cell Resource Center of the Institute of Basic Medical Sciences (CAMS, China). Cells were cultured in Dulbecco's modified Eagle's medium (Hyclone, CA, USA) supplemented with $10 \%$ bovine calf serum (Hyclone), $100 \mathrm{IU} / \mathrm{mL}$ penicillin, and $100 \mathrm{mg} / \mathrm{mL}$ streptomycin (Hyclone) at $37{ }^{\circ} \mathrm{C}$ with $5 \% \mathrm{CO}_{2}$.

\subsection{Cytotoxicity assessment}

Cell viability was determined by the Alamar Blue assay. Cells were seeded in 96-well plates and then treated with AgNPs at various concentrations for $24 \mathrm{~h}$. Then, resazurin (Sigma) was added into culture media at a final concentration of $10 \%(\mathrm{v} / \mathrm{v})$, and cells were cultured for another $2 \mathrm{~h}$. After incubation, fluorescence intensity was detected at an excitation wavelength of $530 \mathrm{~nm}$ with an emission wavelength of $590 \mathrm{~nm}$.

\section{4. $L D H$ release assay}

Cell membrane permeability was evaluated with a commercial kit of lactate dehydrogenase (LDH) release. After treatment with AgNPs for $24 \mathrm{~h}$, culture medium was collected and was then centrifuged at $12,000 \mathrm{~g}$, followed by the analysis of LDH leakage according to the manufacture's instruction (Jiancheng Institute of Biotechnology, Nanjing, China). Levels of LDH were reflected by the changes of $\mathrm{NAD}^{+}$reduction at $490 \mathrm{~nm}$.

\subsection{Localization of silver nanoparticles inside cells by TEM}

K562 cells were treated with AgNP-S, AgNP-M and AgNP-L at 4, 40 and $200 \mu \mathrm{g} / \mathrm{mL}$ for $24 \mathrm{~h}$, respectively, and then washed with phosphate-buffered saline (PBS) 3 times. The harvest cells were fixed with $2.5 \%$ glutaraldehyde and postfixed in $1 \%$ osmium tetroxide. After dehydrated in graded ethanol, cells were cleaned with propylene oxide, treated with a 1:1 mixture of propylene oxide and Spurr's low viscosity resin, and embedded in epoxy resin. Thereafter, the blocks were sectioned and the ultrathin sections (70 $\mathrm{nm}$ ) were stained with $1 \%$ lead citrate and $0.5 \%$ uranyl acetate, followed by examination under a high-resolution transmission electron microscope (JEOL JEM 2010F).

\subsection{Inductively coupled plasma mass spectrometry (ICP-MS) analysis of intracellular Ag mass}

After treatment, K562 cells were washed with PBS and then collected. The harvested cells were digested with mixed acid using a microwave on a MARS machine (CEM Corp., Mattews, NC). Digested samples were finally subjected to ICP-MS assessment using an Agilent 7500 machine (Agilent, Tokyo, Japan), as previously described $[26,27]$.

\subsection{ShRNA knock-down assay}

Full length ODRUL was amplified from human cDNA by PCR and then cloned into the pGEM-T vector. Human ODRUL, PI4K $\alpha$ and Nrf2 shRNA sequences were cloned into shRNA vector PLKO.1, respectively, according to manufacturer's instructions. The primer sequences are shown in Supplementary Table 1. Plasmid transfection was performed, as described in our recent study [28].

\subsection{Cell death determination by flow cytometry}

Cells were collected and washed twice with PBS after treatment with AgNPs for $24 \mathrm{~h}$. Then, cells were stained with $5 \mu \mathrm{L}$ PI solution $(20 \mu \mathrm{g} / \mathrm{mL})$ for $30 \mathrm{~min}$ following the instructions from the manufacturer (BD Biosciences, USA). Dead cells were analyzed by flow cytometry as described previously [28]. To figure out the roles of targeted proteins in cell death, K562 cells were first pre-incubated with specific inhibitors for $1 \mathrm{~h}$ before AgNP treatment. The 
inhibitors were LY 294002 (Sigma-Aldrich, USA), SP600125 (MedChem express, USA), PD98059 (MedChem express, USA) and Stat5 inhibitor (MedChem express, USA).

\subsection{ROS determination}

The generation of intracellular ROS was assessed by fluorescent staining assay. K562 cells were cultured into 96-well plates and exposed to AgNPs at 20 and $40 \mu \mathrm{g} / \mathrm{mL}$ for $6 \mathrm{~h}$. Dichlorofluorescein diacetate (DCF-DA, Sigma) was then added at a final concentration of $10 \mu \mathrm{M}$. After incubation for $30 \mathrm{~min}$, cells were subjected to fluorescence analysis at $525 \mathrm{~nm}$ with excitation at $488 \mathrm{~nm}$.

\subsection{SOD and CAT activities measurement}

Cells after treatment were harvested and then lysed with RIPA buffer for $1 \mathrm{~h}$ at $4{ }^{\circ} \mathrm{C}$. After centrifugation, supernatants were separated for further analysis. The measurements of SOD and CAT activities were performed using assay kits according to the manufacturer's instructions (Jiancheng Institute of Biotechnology, Nanjing, China).

\subsection{RNA-protein pull-down assay and protein identification}

The pGEMT-ODRUL was linearized with restriction enzyme Spe1 (New England Biolabs), and then used to synthesize RNA in vitro by $\mathrm{T} 7$ polymerase according to manufacturer's instruction (Invitrogen, USA). RNA-pull down assay was performed using a commercial RNA-Protein Pull-Down Kit (Thermo Fisher Scientific, USA). Thereafter, RNA-pulled down components were subjected to SDS-PAGE to separate precipitated proteins. Selected protein bands in the gel were identified by mass spectrometry analysis at Beijing Protein Institute. Protein concentrations in the pellets were assessed by Western blot analysis.

\subsection{Real-time $q R T-P C R$ analysis}

Total RNAs from cells were extracted with Trizol reagent according to the manufacturer's instructions (Invitrogen, USA). Two micrograms of total RNAs from different samples were reversetranscribed into cDNA with M-MLV reverse transcriptase (Promega). Expression levels of various IncRNAs and different genes were determined using a standard SYBR Green System. GAPDH was used as an internal control. The primer sequences are shown in Supplementary Table 1.

\subsection{Western blot analysis}

Western blot analysis was performed as described previously $[26,28]$. Cells were washed with cold PBS and then lysed in RIPA lysis buffer supplemented with PMSF and protease inhibitor cocktail. Equal amounts of proteins for each lysate were subjected to sodium dodecyl sulfate-polyacrylamide gel electrophoresis (SDSPAGE) and then transferred to nitrocellulose membranes. The primary antibodies were against Nrf2 (Proteintech, China), HO-1 (Proteintech, China), PI4K $\alpha$ (Proteintech, China), Bcl-2 (Proteintech, China), p-AKT (Cell Signaling Technology, USA), p-JNK (Cell Signaling Technology, USA), p-ERK (Cell Signaling Technology, USA), p-Stat5 (Cell Signaling Technology, USA), and GAPDH (Santa Cruz Biotechnology, USA).

\subsection{Statistical analysis}

All data are expressed as means $\pm \mathrm{SD}$, and statistical analysis was determined by independent $t$-test or One-Way ANOVA test. A p-value less than $0.05\left({ }^{*}\right)$ or 0.001 (\#) indicated significant differences.

\section{Results}

\subsection{Characterization of AgNPs}

We here employed PVP-coated AgNPs with 3 different sizes, termed AgNP-S, AgNP-M and AgNP-L. Prior to cellular treatment, the physicochemical properties of AgNPs were thoroughly characterized. The morphology and size distribution of PVP-coated AgNPs were assessed by TEM. All AgNPs appeared as sphere-like shape without agglomerations (Fig. 1A), and their average diameters calculated from the TEM images were approximately $11 \mathrm{~nm}, 27 \mathrm{~nm}$ and $95 \mathrm{~nm}$, respectively (Fig. 1B). The hydrodynamic diameters were 16.9, 66.5 and $149.9 \mathrm{~nm}$ for AgNP-S, AgNP-M and AgNP-L, respectively, suggesting that the formation of protein corona on AgNP surface $[25,26]$. The zeta-potential analysis showed that all AgNPs were similarly negatively charged (Fig. 1B), in analogy to previous studies $[25,26]$.

\subsection{Determination of cytotoxicity of K562 erythroid cells in response to AgNPs}

To screen the concentrations at which AgNPs would not cause significant cell death, Alamar Blue assay was performed to determine the cell viability of K562 erythroid cells at various concentrations of AgNPs. K562 cells were initially derived from a patient with chronic myelogenous leukemia, and these cells are pluripotent in differentiating into mature erythroid cells, megakaryocytes and monocytes, dependent on differential induction methods $[29,30]$. Thus, K562 cells have been widely used as an in vitro model for the study of normal hematopoiesis, especially for erythroid differentiation, at transcriptional, posttranscriptional, translational and posttranslational levels [31-34]. Moreover, K562 cells are recognized as a desirable model to study the molecular bases underlying stressed erythropoiesis in response to various exogenous stimuli, such as arsenic, UV and anthracyclines [35-37]. Meanwhile, reticulocytes (red blood cells) are often used for the investigation on the translational control of cellular signaling [38]. To this end, K562 cells would be an ideal platform to interrogate genetic and epigenetic regulations on cellular signaling under stressed erythropoiesis [39-41].

As shown in Fig. 2A-C, AgNP-S was more toxic to K562 cells than AgNP-M and AgNP-L, as their calculated IC50 were about 8, 100 and $500 \mu \mathrm{g} / \mathrm{mL}$, respectively. To avoid dramatic cytotoxicity that would mess up mechanistic studies, we thus endeavored to use relatively low concentrations in the following cell treatments: 2 and $4 \mu \mathrm{g} / \mathrm{mL}$ for AgNP-S, 20 and $40 \mu \mathrm{g} / \mathrm{mL}$ for AgNP-M and 100 and $200 \mu \mathrm{g} / \mathrm{mL}$ for AgNP-L, respectively. Corroborated with the cytotoxicity data, AgNPs at lower concentrations did not massively increase the extracellular LDH release, compared to untreated control (Fig. 2D).

Our previous study suggested that AgNPs could translocate into erythroid cells through the "Trojan Horse effect" [25]. The TEM images revealed that AgNPs could localize inside k562 cells, mostly in phagosomes (Fig. 2E), similar to previous findings [25,42]. In addition, we quantified the Ag contents in K562 cells upon AgNP treatment for $24 \mathrm{~h}$ through ICP-MS analysis, and the results are shown in Fig. 2F. A greater Ag accumulation was found in cells upon exposure to AgNP-M and AgNP-L, especially for the latter, compared to AgNP-S (Fig. 2F, P < 0.001). The elevated cellular uptake of Ag particles by cells upon AgNPs of larger sizes may be attributed to higher concentrations used for them, although they induced comparable toxicity to K562 cells. These results 

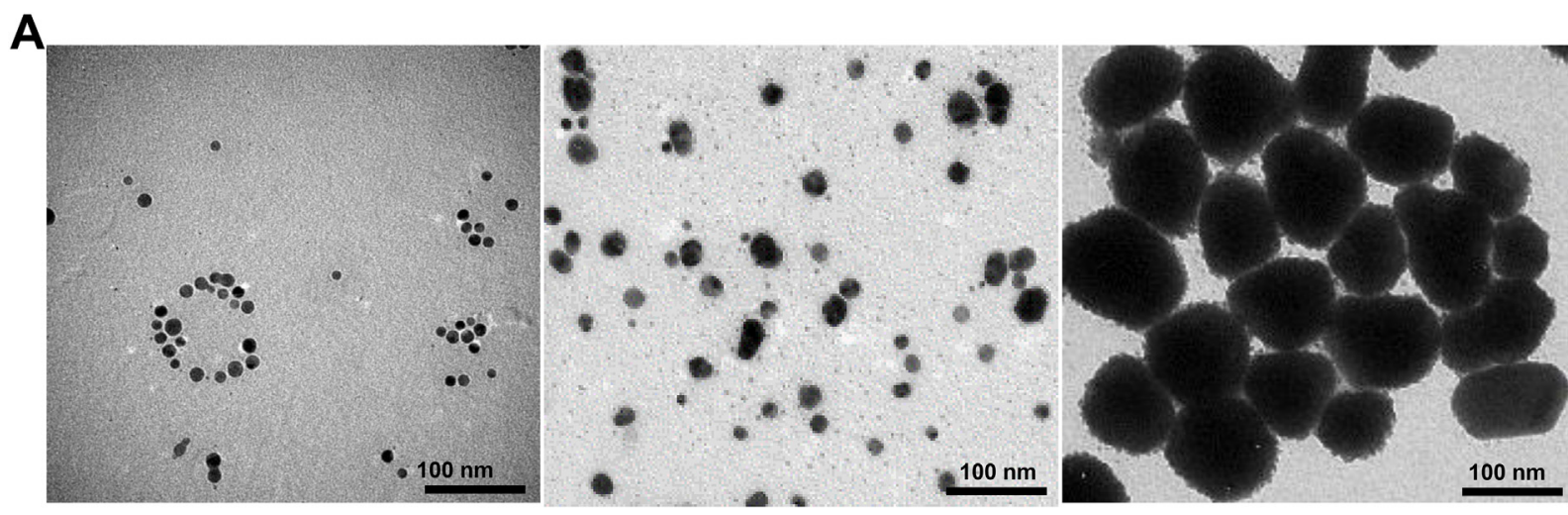

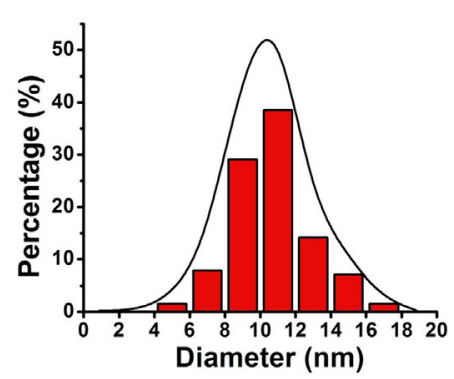

AgNP-S

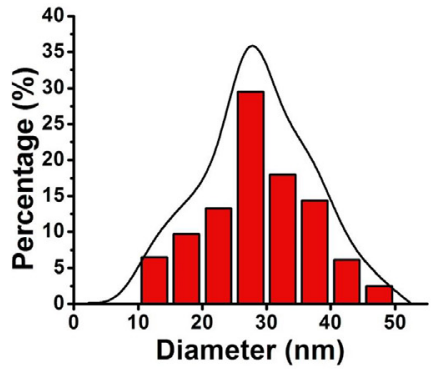

AgNP-M

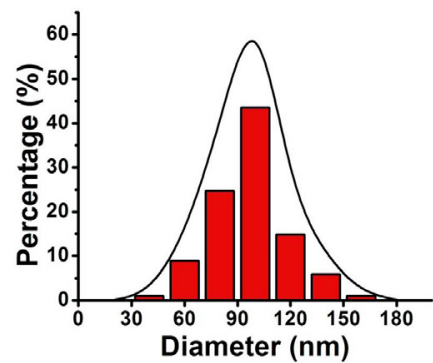

AgNP-L

B

\begin{tabular}{lcc}
\hline & Hydrodynamic diameters $(\mathrm{nm})$ & $\zeta$-potential \\
\hline AgNP-S & $16.85 \pm 0.33$ & $-16.66 \pm 1.06$ \\
AgNP-M & $66.49 \pm 0.09$ & $-16.25 \pm 0.21$ \\
AgNP-L & $149.85 \pm 5.94$ & $-18.64 \pm 0.66$ \\
\hline
\end{tabular}

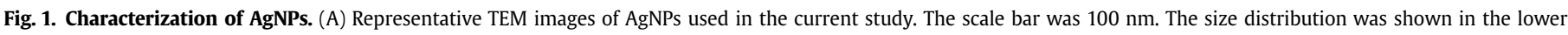

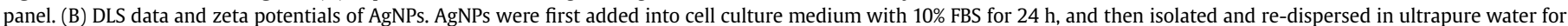
the analysis of hydrodynamic diameters and zeta potentials $(n=3)$.

demonstrated that AgNPs readily intruded into K562 cells, giving rise to potential cellular damage.

\subsection{LncRNA ODRUL regulates AgNP-induced cytotoxicity}

To investigate whether IncRNAs contribute to the regulation of AgNP-induced cytotoxicity of erythroid cells, we deliberately looked into the expression of lncRNAs in K562 cells in response to AgNPs. First, 27 lncRNAs were selected based on their reported functions with relevance to erythroid cell survival or differentiation. As shown in Fig. 3A, a few IncRNAs were significantly elevated or repressed in K562 cells treated with AgNP-M at $40 \mu \mathrm{g} / \mathrm{mL}$ for $24 \mathrm{~h}$ to a differential extent, including ODRUL, PTENP, LincRNAROR, PVTI and H19 ( $\mathrm{P}<0.05)$. Among these altered lncRNAs, the greatest change was observed for ODRUL (osteosarcoma doxorubicin-resistance related up-regulated lncRNA), with nearly a 10 -fold induction in cells upon AgNP-M exposure $(\mathrm{P}<0.001)$. To substantiate this observation, AgNP-M was subjected to cellular treatment at different time points. As shown in Fig. 3B, the level of ODRUL was significantly increased in K562 cells upon AgNP-M treatment for $3 \mathrm{~h}, 12 \mathrm{~h}$ and $24 \mathrm{~h}(\mathrm{P}<0.05)$, displaying that AgNP$\mathrm{M}$ quickly initiated ODRUL induction. To look into size- dependency, K562 cells were exposed to AgNP-S and AgNP-L separately. As shown in Fig. $3 \mathrm{C}$ and D, a great induction of ODRUL expression was observed in K562 cells responding to both AgNP-S and AgNP-L $(\mathrm{P}<0.001)$, and a dose-dependent increase was found in AgNP-L-treated cells, relative to untreated cells $(\mathrm{P}<0.05)$. These data indicated that all AgNPs at a comparable toxicity level induced ODRUL expression, but without showing significant size dependence. Previous studies have demonstrated the crucial role of particle size in determining the AgNP-induced cytotoxicity [7,43]. Therefore, more efforts are needed to address the exact dependence of ODRUL expression on size in response to AgNPs. Since all 3 sized AgNPs could robustly promote the increase of ODRUL and they manifested differential IC50 values, we here used AgNP-M (abbreviated as AgNPs) as the representative material for detailed mechanistic studies in the following experiments.

To validate the hypothesis that IncRNA ODRUL plays a crucial role in dictating AgNP-induced toxicity, stable ODRUL knockdown transfectants (here named ODRUL-low cells) were obtained through the lentiviral shRNA approach. As shown in Fig. 4A, the endogenous ODRUL level was diminished by $75 \%$ in ODRUL-low cells, relative to that in scrambled control cells $(P<0.05)$. Accordingly, the ODRUL levels were much lower in ODRUL-low cells upon 
A

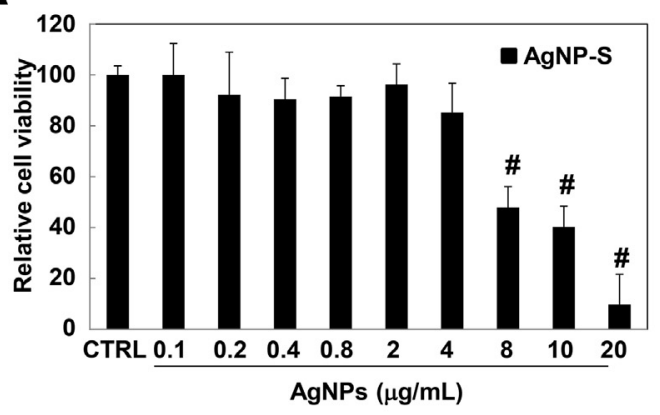

C

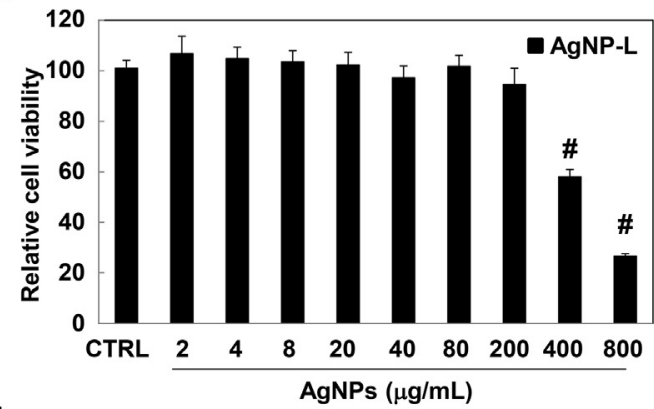

E
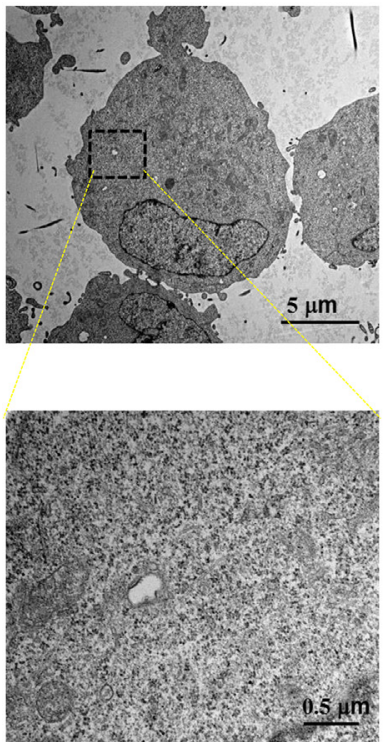

CTRL
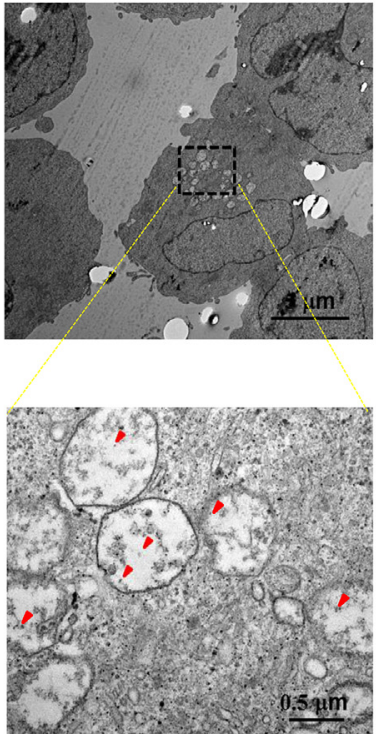

AgNP-S
B

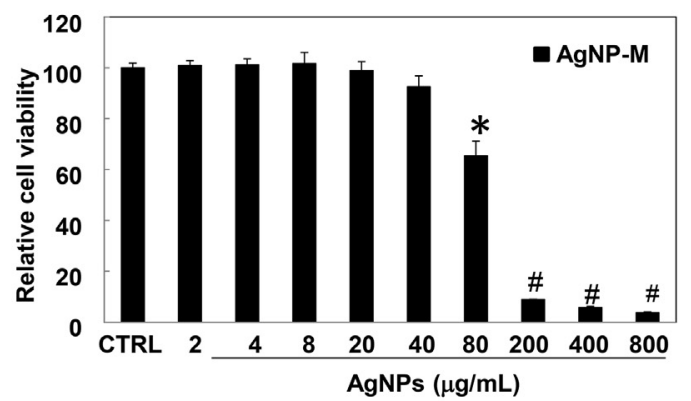

D

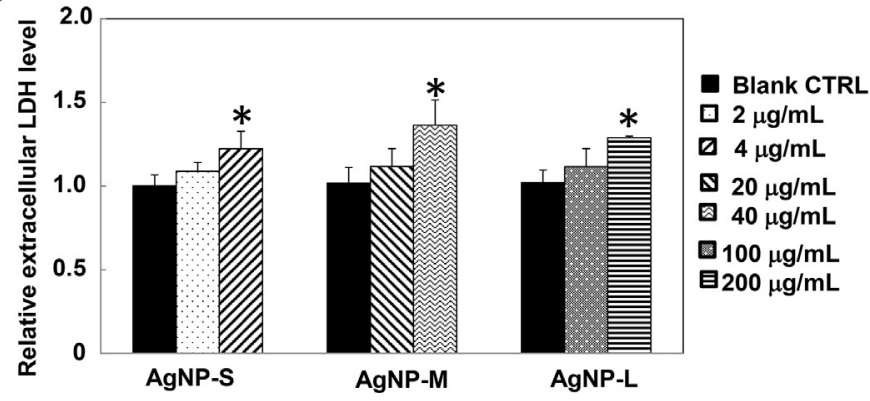

F

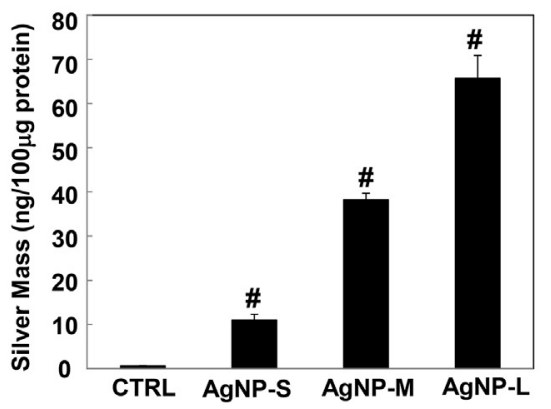

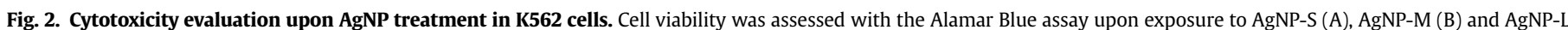

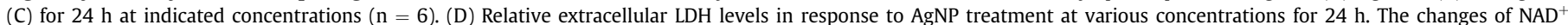

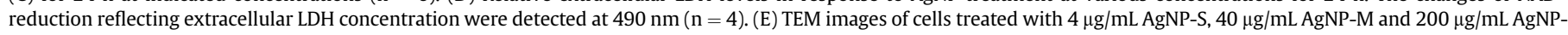

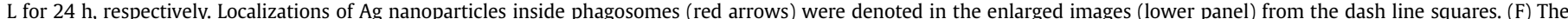

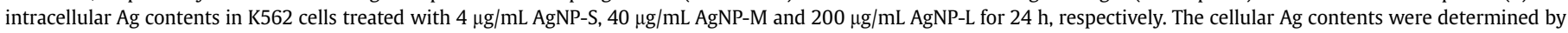
ICP-MS assay $(\mathrm{n}=4)$. (For interpretation of the references to colour in this figure legend, the reader is referred to the web version of this article.) 

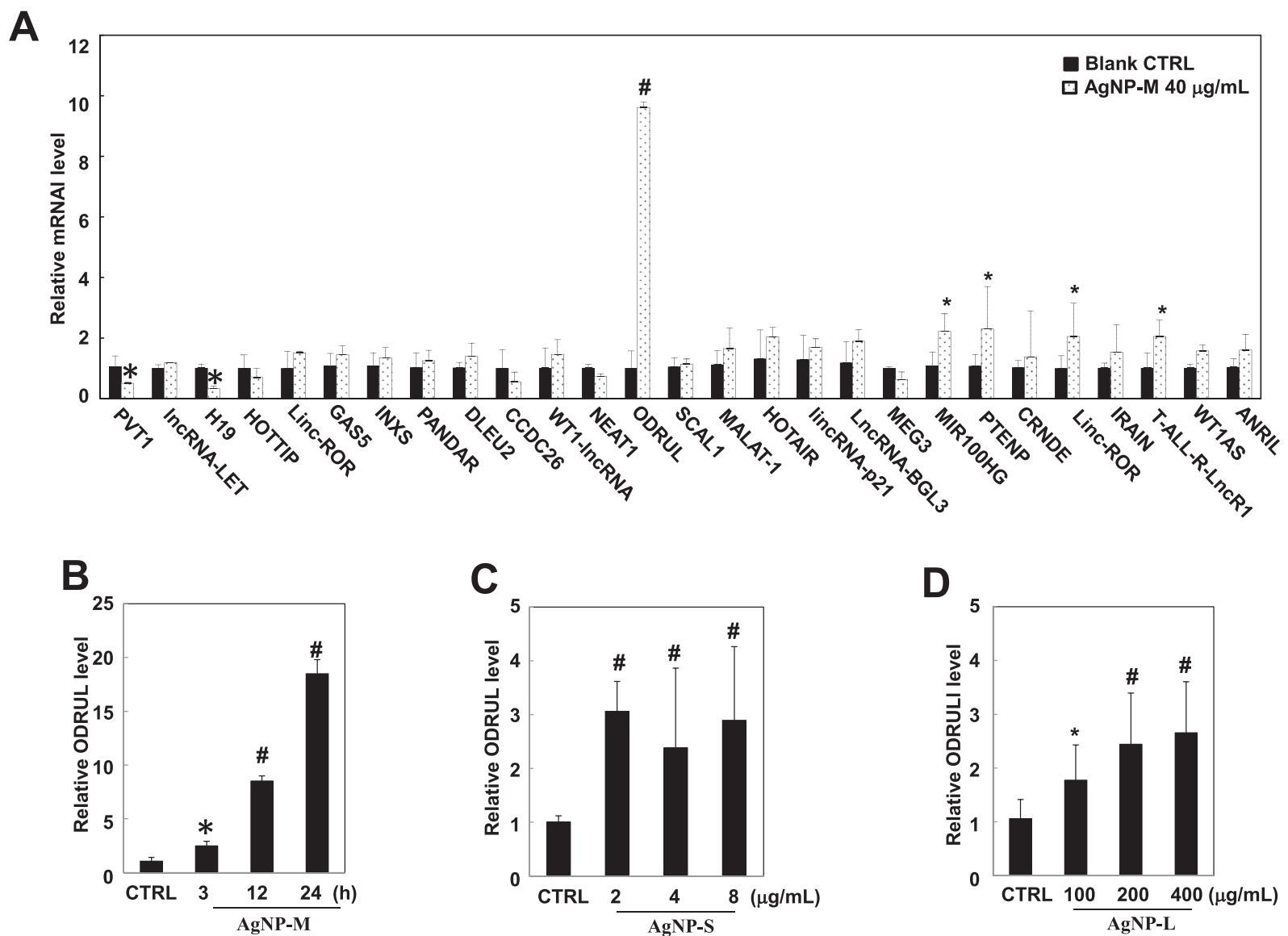

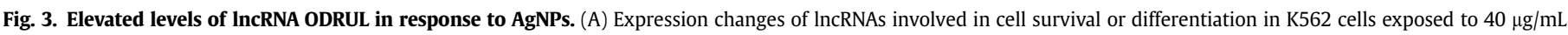

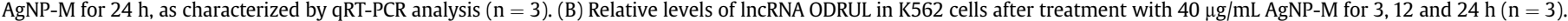
ODRUL mRNA levels upon exposure to AgNP-S (C) and AgNP-L (D) at indicated concentrations for $24 \mathrm{~h}$, as determined by qRT-PCR assay ( $\mathrm{n}=3$ ).

AgNP treatment, with approximately $57 \%-78 \%$ reduction in comparison to AgNP-treated scrambled control cells (Fig. 4A, P < 0.05). We then evaluated the cytotoxicity of AgNPs to ODRUL-low cells. As shown in Fig. 4B, the reduction of cell viability was greatly reversed in ODRUL-low cells upon AgNP treatment at various concentrations $(P<0.05)$. The viability of ODRUL-low cells upon AgNPs was comparable to that of untreated control, in contrast to $27-42 \%$ reduction of cell viability in scrambled control cells. This finding suggested that AgNPs did not induce sufficient toxicity to cells without a comparable level of ODRUL. In support of this finding, cell death examination also revealed similar reversion of PI-positive proportion in ODRUL-low cells in comparison to scrambled control cells upon AgNP treatments (Fig. 4C, $\mathrm{P}<0.05$ ). The proportion of PI-positive cells in ODRUL-low cells was reduced by approximately 50\%, compared to scrambled control cells after 24 and 48 htreatment of AgNPs, and a bigger difference was found at $48 \mathrm{~h}$ than that at $24 \mathrm{~h}$ (Fig. 4C, $\mathrm{P}<0.05$ ). Together, these findings demonstrated that AgNPs elicited toxicity to K562 cells, at least partially, through inducing lncRNA ODRUL expression.

\subsection{Relatively specific response of ODRUL induction by AgNPS}

To look into the possible induction of ODRUL by other nanoparticles, we detected the ODRUL expression levels in K562 erythroid cells upon treatment with $\mathrm{ZnO}$ and $\mathrm{TiO}_{2}$ nanoparticles (here named $\mathrm{nZnO}$ and $\mathrm{nTiO}_{2}$ ). First, the cell viability and ROS production were determined in cells treated with $\mathrm{nZnO}$ and $\mathrm{nTiO}_{2}$. Our results showed that $\mathrm{nZnO}$ incurred more reduction of cell viability, compared to $\mathrm{nTiO}_{2}$ at the same mass concentrations (Supplementary Figs. 1A and B, $\mathrm{P}<0.05$ ), consistent with previous reports $[44,45]$. Therefore, we chose the concentrations that elicited a similar degree of toxicity to $\mathrm{K} 562$ cells for $\mathrm{nZnO}$ and $\mathrm{nTiO}_{2}$ for further study. At these defined concentrations, both $\mathrm{nZnO}$ and $\mathrm{nTiO}_{2}$ greatly induced the production of ROS by approximately 2 fold (Supplementary Fig. 1C, $\mathrm{P}<0.001$ ). Meanwhile, nZnO and $\mathrm{nTiO}_{2}$ exerted no effect on the levels of ODRUL (Supplementary Fig. 1D, P > 0.05). Moreover, Ag ions are believed to contribute to ROS generation and the overall cytotoxicity induced by AgNPs $[46,47]$. To determine the possible stimulating effects of Ag ions on ODRUL expression, we also looked at ODRUL expression in K562 cells treated with $\mathrm{Ag}$ ions. Since the proportion of $\mathrm{Ag}$ ions dissolved from AgNPs was small [25], Ag ions at low concentrations were used to treat K562 cells. As shown in Supplementary Fig. 2, Ag ions induced lncRNA ODRUL expression $(P<0.05)$, suggesting that dissolved $\mathrm{Ag}$ ions also contributed to ODRUL induction under AgNP-stimulated oxidative stress. Collectively, these findings uncovered a relatively specific response of ODRUL induction upon AgNPs relative to other nanoparticles, although more experiments are needed to elucidate the underlying molecular mechanisms, such as implications of $\mathrm{Ag}$ ions and protein coronas.

\subsection{ODRUL expression is regulated by Nrf2 upon AgNP-induced oxidative stress}

Thereafter, we looked into the molecular mechanisms responsible for ODEUL induction in K562 cells upon AgNP treatment. Since 
A

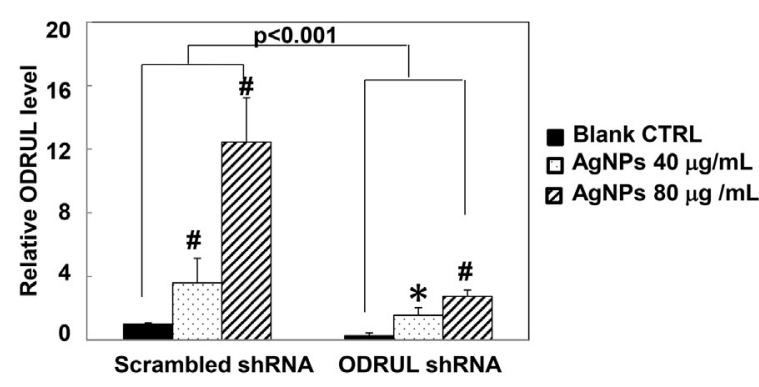

B

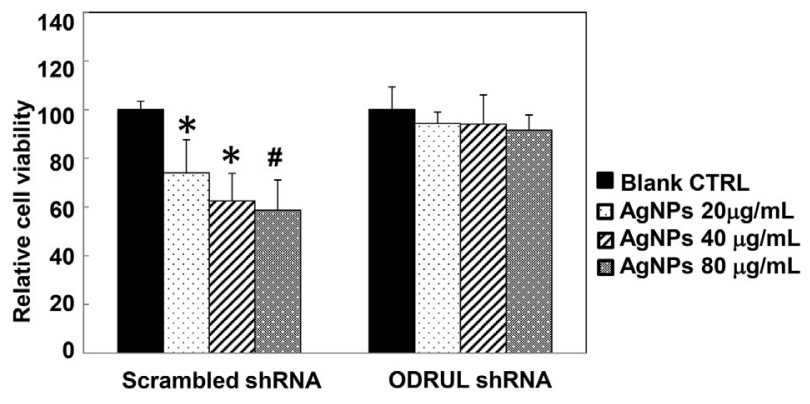

$48 \mathrm{~h}$

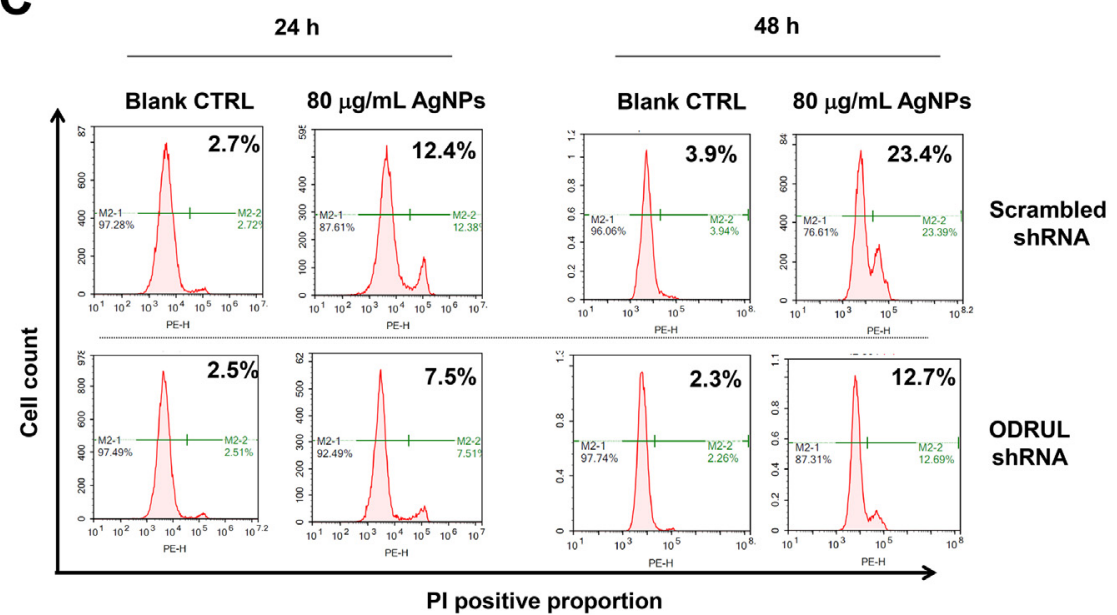

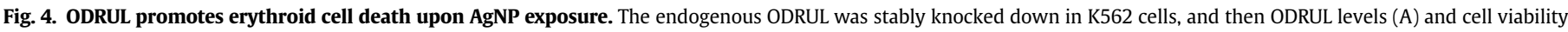

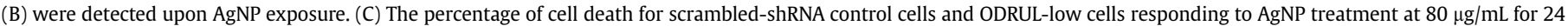
and 48 h. Cell death was determined through flow cytometry analysis with PI staining $(\mathrm{n}=3)$.

oxidative stress has been demonstrated to be the most important mechanism underlying AgNP-associated cytotoxicity $[48,49]$, we assayed the generation of ROS in $\mathrm{K} 562$ cells responding to AgNP exposure. As shown in Fig. 5A, a 30-40\% increase of intracellular ROS was found in K562 cells upon AgNP treatment at 20 and $40 \mu \mathrm{g} /$ $\mathrm{mL}(\mathrm{P}<0.05)$. Consistent with this result, the activity of superoxide dismutase (SOD) was largely elevated, while the activity of catalase (CAT) was repressed in treated cells (Supplementary Figs. 3A and B, $\mathrm{P}<0.05)$. These data collectively demonstrated that AgNPs induced significant cellular oxidative stress. In view of the results of cell viability (Figs. 2B and 4B), we hypothesized that AgNP-induced oxidative stress promoted the ODRUL induction. Herein the effect of $\mathrm{N}$-acetyl-l-cysteine (NAC), a potent ROS scavenger, on ODRUL induction was evaluated. As shown in Fig. 5B, the induction of ODRUL expression by AgNPs was greatly reversed by more than $50 \%$ with NAC pre-treatment $(P<0.05)$.

$\mathrm{Nrf} 2$ is a master transcription factor in regulating the expression of oxidative stress-related genes against stress-associated toxicity [50]. We then assessed the concentration of Nrf2 in K562 cells upon AgNP treatment at different concentrations. As shown in Fig. 5C, a pronounced elevation of $\mathrm{Nrf} 2$ concentration was found in cells in a dose-dependent manner. As a downstream target of Nrf2, the level of heme oxygenase-1 (HO-1) was similarly enhanced in the presence of AgNPs (Fig. 5C). In addition, Nrf2-HO-1 pathway was activated over time after exposure to $40 \mu \mathrm{g} / \mathrm{mL}$ AgNPs (Supplementary Fig. 4). To scrutinize the role of $\mathrm{Nrf} 2$ in ODRUL-determined signaling pathway, we further stably knocked down endogenous Nrf2 expression (here termed Nrf2-low cells) (Supplementary Fig. 5 and 5D). Nrf2 concentration was remarkably diminished in Nrf2low cells in comparison with scrambled control cells upon AgNP treatment (Fig. 5D). ODRUL induction by AgNPs was also inhibited to the baseline level in Nrf2-low cells (Fig. 5E, P $<0.05$ ), and cell death was greatly diminished after 24 and 48 h-treatment of AgNPs, especially for 48 h-treatment (Fig. $5 \mathrm{~F}, \mathrm{P}<0.05$ ). These results indicated that Nrf2 might directly regulate the expression of ODRUL, similar to other lncRNAs such as ROR and SCAL1 [51,52].

3.6. Phosphatidylinositol (PI) 4-kinase alpha (PI4K $\alpha$ ) is a partner of ODRUL in bridging the signaling pathways responsible for AgNPinduced toxicity

Previous studies have revealed that IncRNAs interact with partner proteins (e.g., chromatin-modifying enzymes and transcriptional regulators) to fine-tune gene expressions $[18,53]$. We thus surveyed the partners that were necessary for the signaling transduction in AgNP-induced cytotoxicity. As shown in Fig. 6A, the biotin-labeled full length ODRUL RNA probes pulled down much more proteins than biotin-nonsense RNA probes in erythroid cell lysates. Mass spectrometry analysis identified these proteins, and, among them, PI4K $\alpha$ was recognized (Supplementary Table 2). Western blot analysis further substantiated the interaction between ODRUL and PI4K $\alpha$ (Fig. 6B). To understand the role of this interaction in AgNP-induced cytotoxicity, stable PI4K $\alpha$-knockdown (termed as PI4K $\alpha$-low) cells were obtained through lentiviral shRNA (Supplementary Fig. 6, P $<0.05$ ). Reduced PI4K $\alpha$ was demonstrated before and after AgNP treatment (Fig. 6C). AgNP- 
A

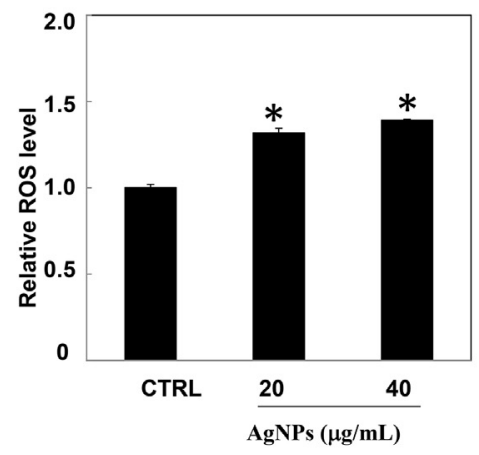

B

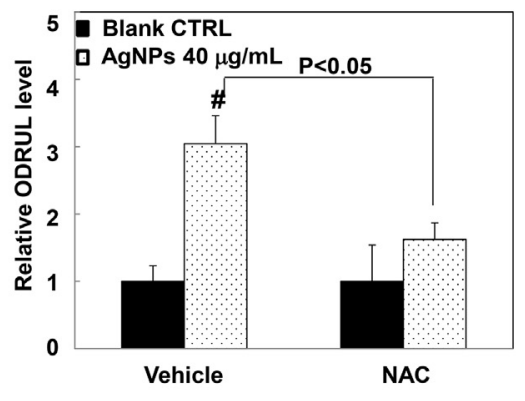

C

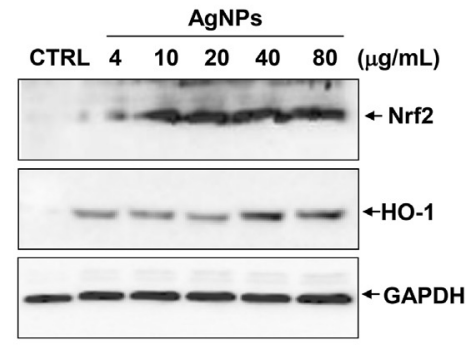

D

Scrambled shRNA Nrf2 shRNA

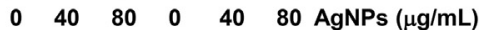

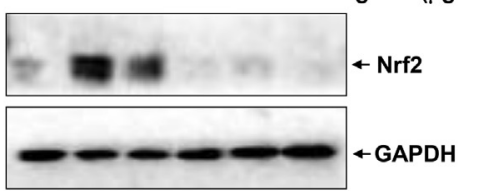

$\mathbf{E}$

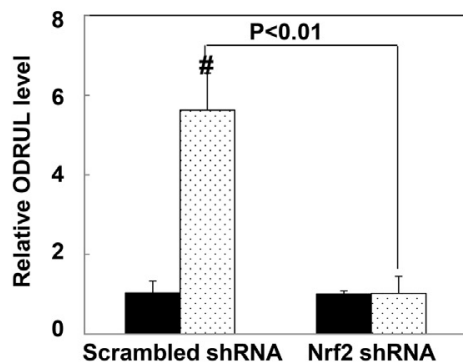

Blank CTRL

- AgNPs $40 \mu \mathrm{g} / \mathrm{mL}$

$\mathbf{F}$

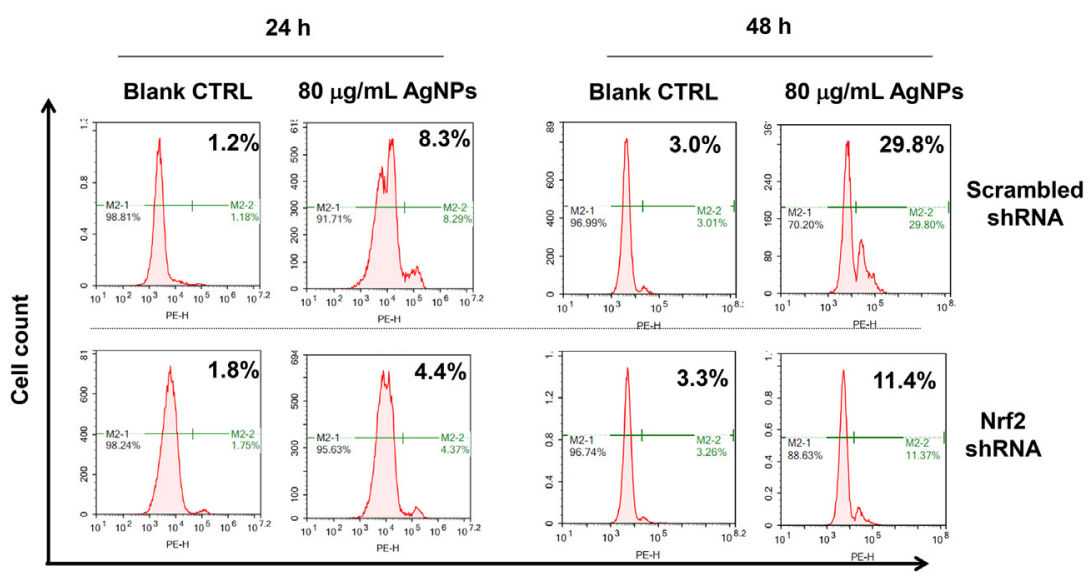

PI positive proportion

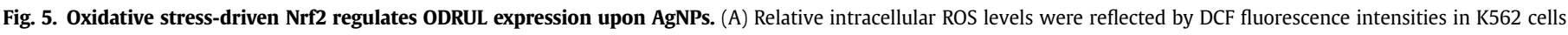

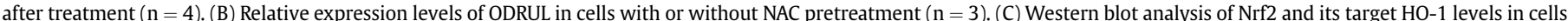

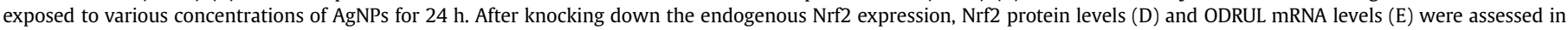

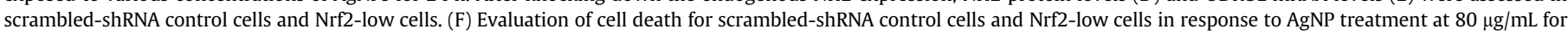
24 and $48 \mathrm{~h}$ through flow cytometry analysis with PI staining $(\mathrm{n}=3)$.

induced cytotoxicity was exacerbated by approximately $80 \%$ in PI4K $\alpha$-low cells, compared to that in scrambled-shRNA control cells (Fig. 6D), demonstrating the protective role of PI4K $\alpha$ against stress $[54,55]$. Together, these results revealed that AgNP-induced ODRUL interacted with PI4K $\alpha$, which led to the inhibition of PI4K $\alpha$ activity and consequently a great increase in cellular death.

\subsection{AKT and JNK are the downstream targets of the ODRUL/PI4K $\alpha$ complex}

To explore the downstream signaling events of ODRUL/PI4K $\alpha$ complex, we further determined PI4K $\alpha$ 's targets. As shown in Fig. 7A, the phosphorylation of AKT, JNK, Stat5 and ERK were enhanced in a dose-dependent manner. The increases of the phosphorylation for these kinases were also found in K562 cells upon AgNP treatment over the course of time (Fig. 7B). To figure out the roles of these proteins in AgNP-induced cytotoxicity, selective inhibitors were used. As shown in Fig. 7C, the inhibition of AKT phosphorylation increased AgNP-induced cell death by 1.8 folds, compared to the vehicle control $(\mathrm{P}<0.05)$. In contrast, the blockage of JNK pathway abrogated cell death from 9.7\% in AgNP-treated cells without the JNK inhibitor to 5.5\% in AgNP-treated cells with 


\section{A}

Biotin-NS Biotin-ODRUL Marker

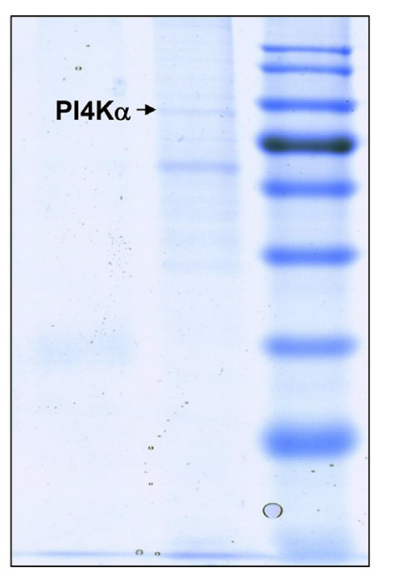

\section{C}

Scrambled shRNA PI4K $\alpha$ shRNA

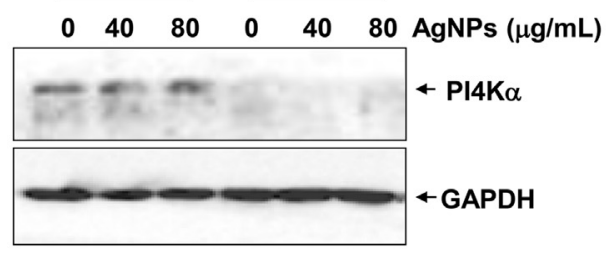

B

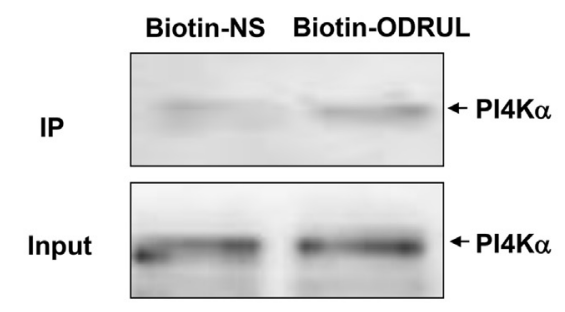

D

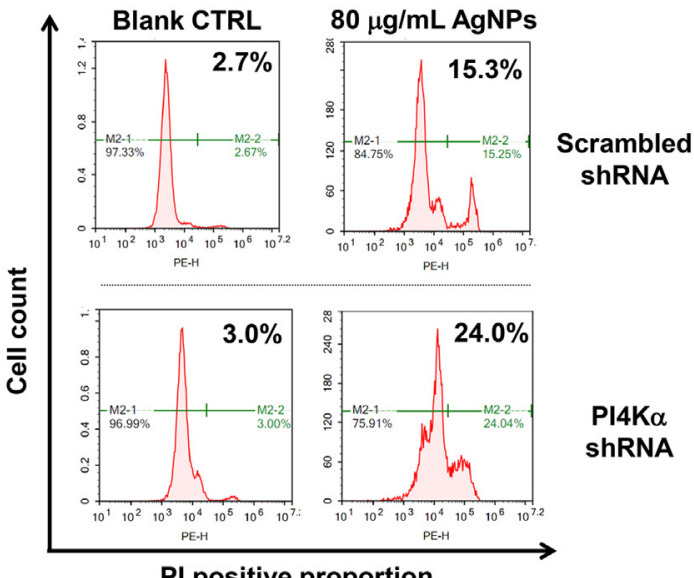

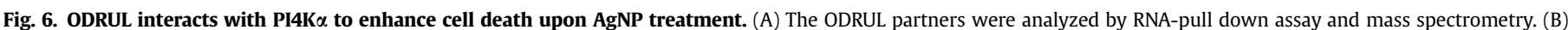

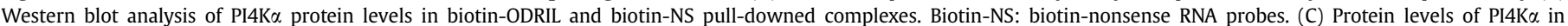

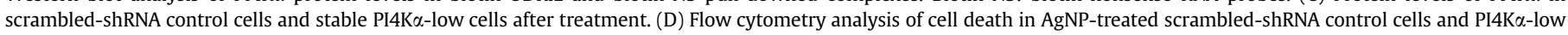
cells $(\mathrm{n}=3)$.

the JNK inhibitor (Fig. 7C, $\mathrm{P}<0.05$ ). However, this abrogation conducted by the JNK inhibitor did not reverse cell death to the baseline level, as $2.9 \%$ cell death in vehicle control group and $3.5 \%$ in cells treated with the inhibitor only (Fig. $7 C, \mathrm{P}<0.05$ ). These data suggested that blocking the JNK pathway only partially suppressed AgNP-induced cell death. Nevertheless, inhibitions on ERK and Stat5 signaling did not alter the toxicity (Fig. 7C). Therefore, AKT and JNK pathways were more important in modulating cell survival upon AgNP treatment.

To further confirm the relationship between PI4K $\alpha$ and the activation of AKT and JNK signaling pathways, we investigated phosphorylation status of AKT and JNK in ODRUL-low cells and PI4K $\alpha$-low cells. AKT phosphorylation was enhanced whereas JNK phosphorylation was repressed in ODRUL-low cells upon AgNP treatment, compared to scrambled-shRNA cells (Fig. 7D). Conversely, AKT phosphorylation was diminished and JNK phosphorylation was increased in PI4K $\alpha$-low cells (Fig. 7E). These results signified that ODRUL/PI4K $\alpha$ complex reduced AKT activity and increased JNK activity, resulting in enhanced cell death in response to AgNP treatment.

\section{8. $\mathrm{Bcl}-2$ is the final executor of ODRUL/PI4K $\alpha$ complex in dictating} cell death

To search the final executors of ODRUL/PI4K $\alpha$ complex, we screened the changes of the key targets of AKT and JNK signaling that are involved in cell survival regulation, including $\mathrm{Bcl}-2, \mathrm{BAX}$, Bcl-xL, Survivin, PTEN and CCND1. As shown in Fig. 8A-C, only Bcl2 was significantly upregulated upon AgNP treatment at both mRNA and protein levels in a dose and time-dependent manner $(\mathrm{P}<0.05)$. It should be noted that, although an increase of Bcl-xL at mRNA level was observed (Fig. 8A, $\mathrm{P}<0.001$ ), no increase was demonstrated at the protein level (Supplementary Figs. 7A and B). In addition, our results also showed that the protein levels of BAX were not altered responding to AgNPs (Supplementary Figs. 7A and $\mathrm{B})$, indicating that BAX was not involved in AgNP-induced erythroid cell death. Therefore, we only focused on $\mathrm{Bcl}-2$ for further investigation.

Since Bcl-2 is crucial in preventing cell death [56], the induction of ODRUL indeed antagonized the function of Bcl-2 under AgNP stress. We looked at the expression of Bcl-2 in ODRUL-low cells 
A

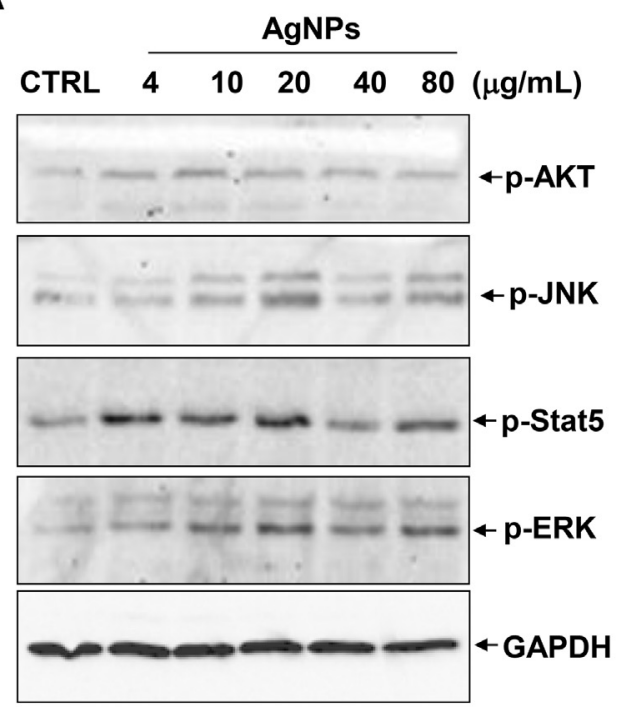

B
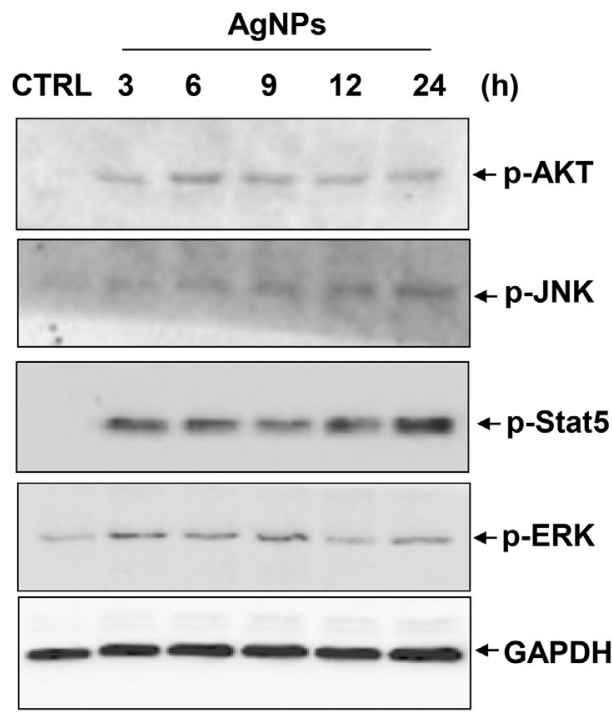

C

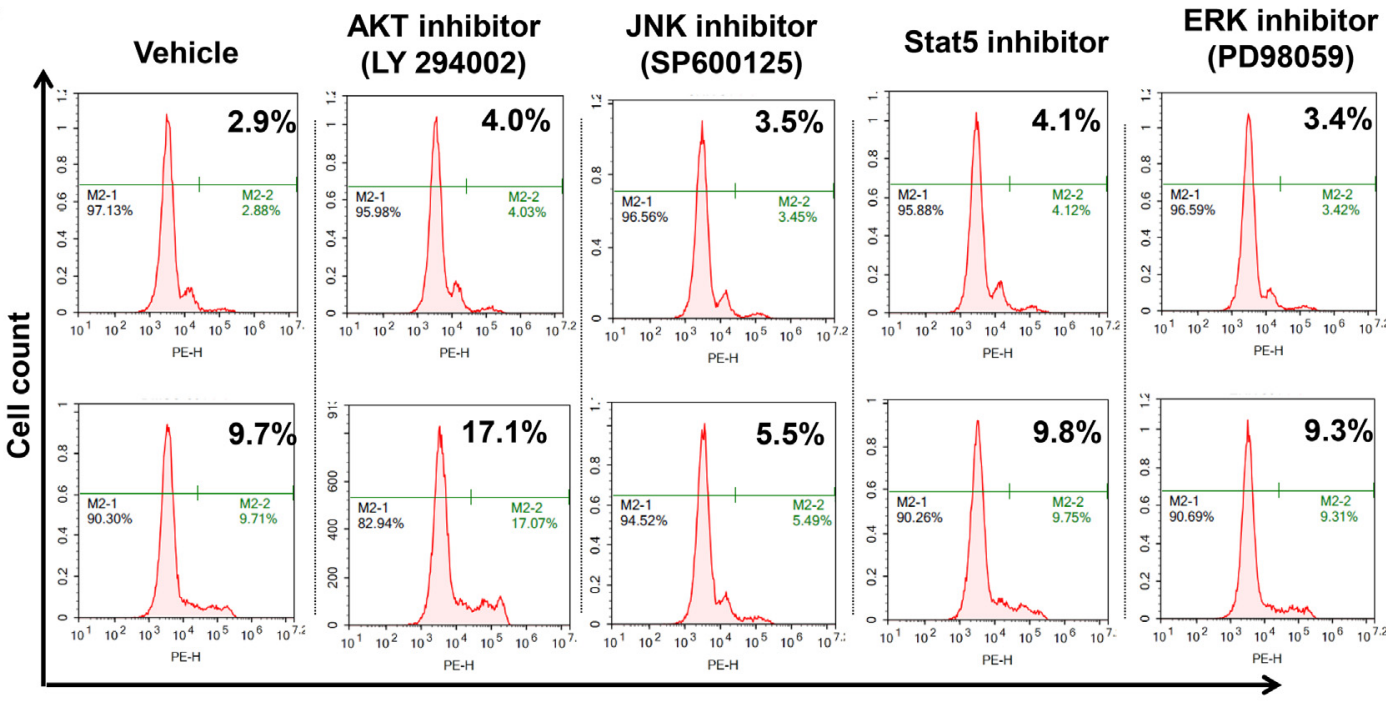

Blank

CTRL

PI positive proportion

D

Scrambled shRNA ODRUL shRNA

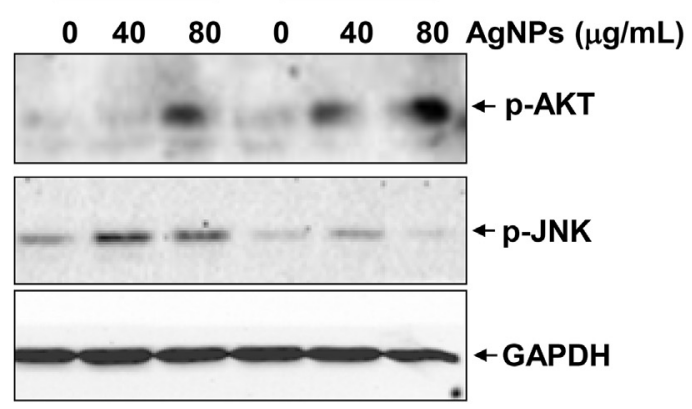

E

Scrambled shRNA PI4K $\alpha$ shRNA

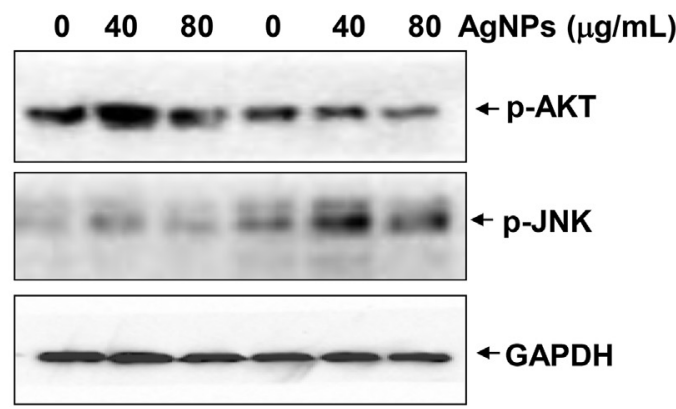

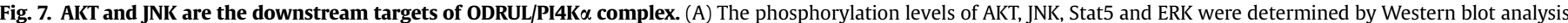

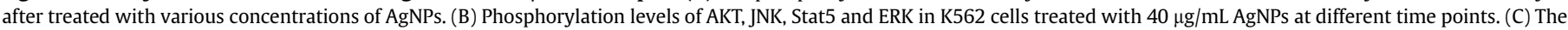

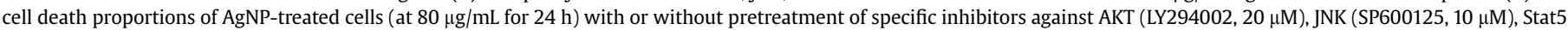

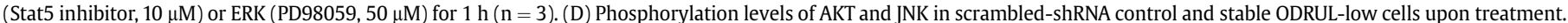

(E) AKT and JNK activation in scrambled-shRNA control and PI4K $\alpha$-low cells. 
A

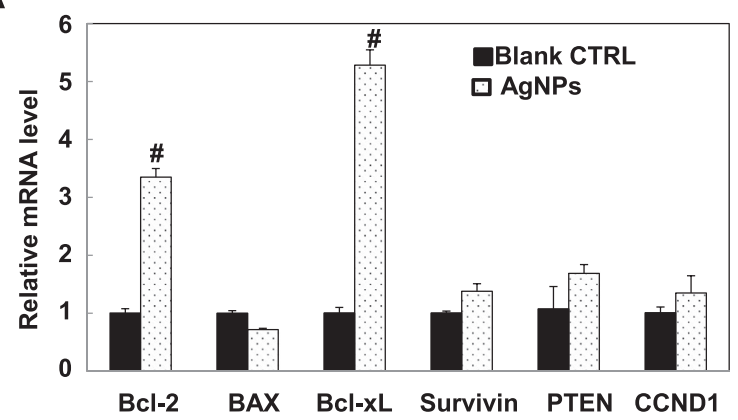

C

AgNPs

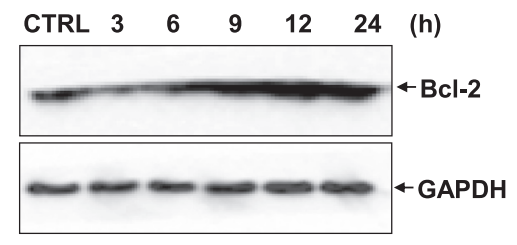

B

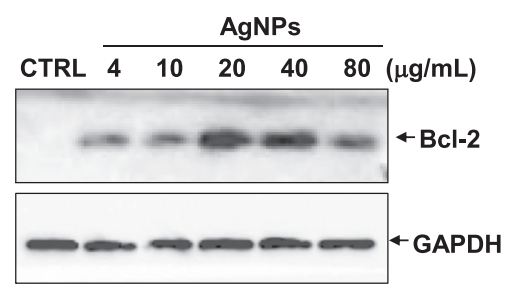

D

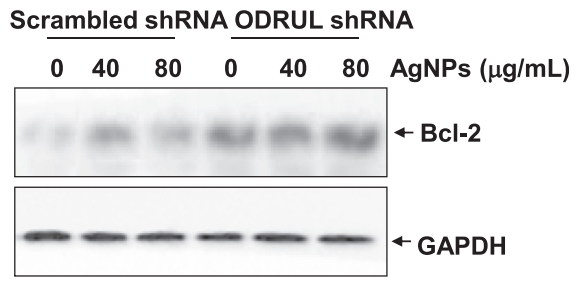

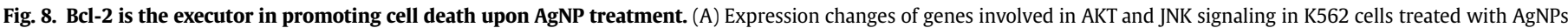

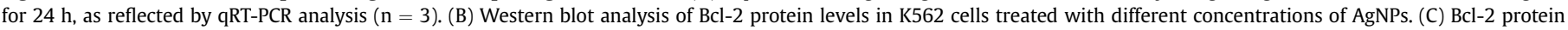

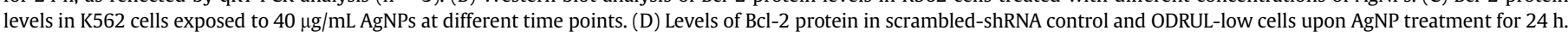

responding to AgNPs. A significant induction of Bcl-2 concentration was observed in ODRUL-low cells upon AgNP treatment, similar to scrambled-shRNA control cells (Fig. 8D). AKT and JNK are two important kinases that modulate cell death through regulating hundreds of kinases and transcription factors [57-59]. Previous reports have verified the activation of AKT by PI4K $\alpha$ [60]. Moreover, the activation of AKT signaling could inhibit JNK activity through interacting with its upstream kinases, such as ASK1 and MKK4/7 [61]. Therefore, based on our results, we assumed that ODRUL posed an inhibition on PI4K $\alpha$-AKT-Bcl-2 signaling and also enforced the blockade of JNK on Bcl-2 through the AKT-JNK crosstalk in K562 cells upon AgNPs. These data together revealed that ODRUL/ $\mathrm{PI} 4 \mathrm{~K} \alpha-\mathrm{AKT} / \mathrm{JNK}$ signaling concertedly promoted erythroid cell death by sequestering the function of Bcl-2 in erythroid cells upon AgNP-conducted stress.

\section{Discussion}

A large number of studies have described the toxicities of AgNPs in vitro and in vivo at multiple organism levels [6,7,62], and oxidative stress and direct or indirect activation of associated pathways are assumed to be predominantly responsible for AgNPinduced cytotoxicity [63]. However, the molecular bases that dictate the activation of the stress signaling pathways remain elusive. In the current study, we identified that IncRNA ODRUL linked the oxidative stress to downstream cytotoxic signaling to trigger AgNP-induced cell death in K562 erythroid cells. ODRUL was for the first time recognized as a novel target of Nrf2, and its expression was greatly induced by $\mathrm{Nrf} 2$ in erythroid cells responding to AgNPs. Nrf2 is the master regulator to combat oxidative stress in mammalian cells by targeting a number of antioxidant genes, such as HO-1, NQO1 and GST [64]. Different from other targets, Nrf2-driven ODRUL induction was found to play an indispensable role in enhancing AgNP-induced cell death through antagonizing the function of Bcl-2. Thus, this is the first report on a pro-apoptotic role of Nrf2 through preventing the function of Bcl-2 dependent on IncRNA ODRUL.

ODRUL was first discovered to be a IncRNA upregulated in tumor specimens from osteosarcoma patients, and it was found to play a critical role in promoting doxorubicin resistance for osteosarcoma cells through regulating the expression of ATP-binding cassette, subfamily $B$, member 1 (ABCB1) gene [4]. In terms of drug resistance, IncRNA Linc-VLDLR also contributed to chemoresistance through regulating the expression of ATP-binding cassette, subfamily G member 2 (ABC-G2) [65], suggesting a similar action mode for lncRNAs to confer cancers cells with a capability of drug resistance. However, our results unearthed a novel function of ODRUL in promoting erythroid apoptosis upon AgNP exposure through regulation of AKT/JNK-Bcl-2 signaling that is dependent on a physical interaction with PI4K $\alpha$. Therefore, our current data pinpointed that AgNP-induced ODRUL accounted for enhanced cell death, which is different from drug resistance, as previously discussed $[4,65,66]$. To this end, we here deciphered a mechanism responsible for ODRUL-modulated cell death under AgNP-induced stress. Although the detailed mechanism responsible for the interaction between ODRUL and PI4K $\alpha$ needs further investigation, our results demonstrated that the binding of ODRUL with PI4K $\alpha$ in fact impeded the pro-survival role of PI4K $\alpha$. PI4Ks are the inositol lipid kinase that catalyzes phosphoinositide into phosphatidylinositol 4,5-bisphosphate [67,68]. PI4K $\alpha$ provides the substrate (PtdIns 4,5-P2) for PI3K and subsequently induces the activation of AKT [60]. Thus, the increase of ODRUL would prevent the activation of AKT by PI4K $\alpha$, resulting in an inhibition on Bcl-2 in AgNP-treated K562 cells. In addition, AKT acts to suppress the activity of JNK 


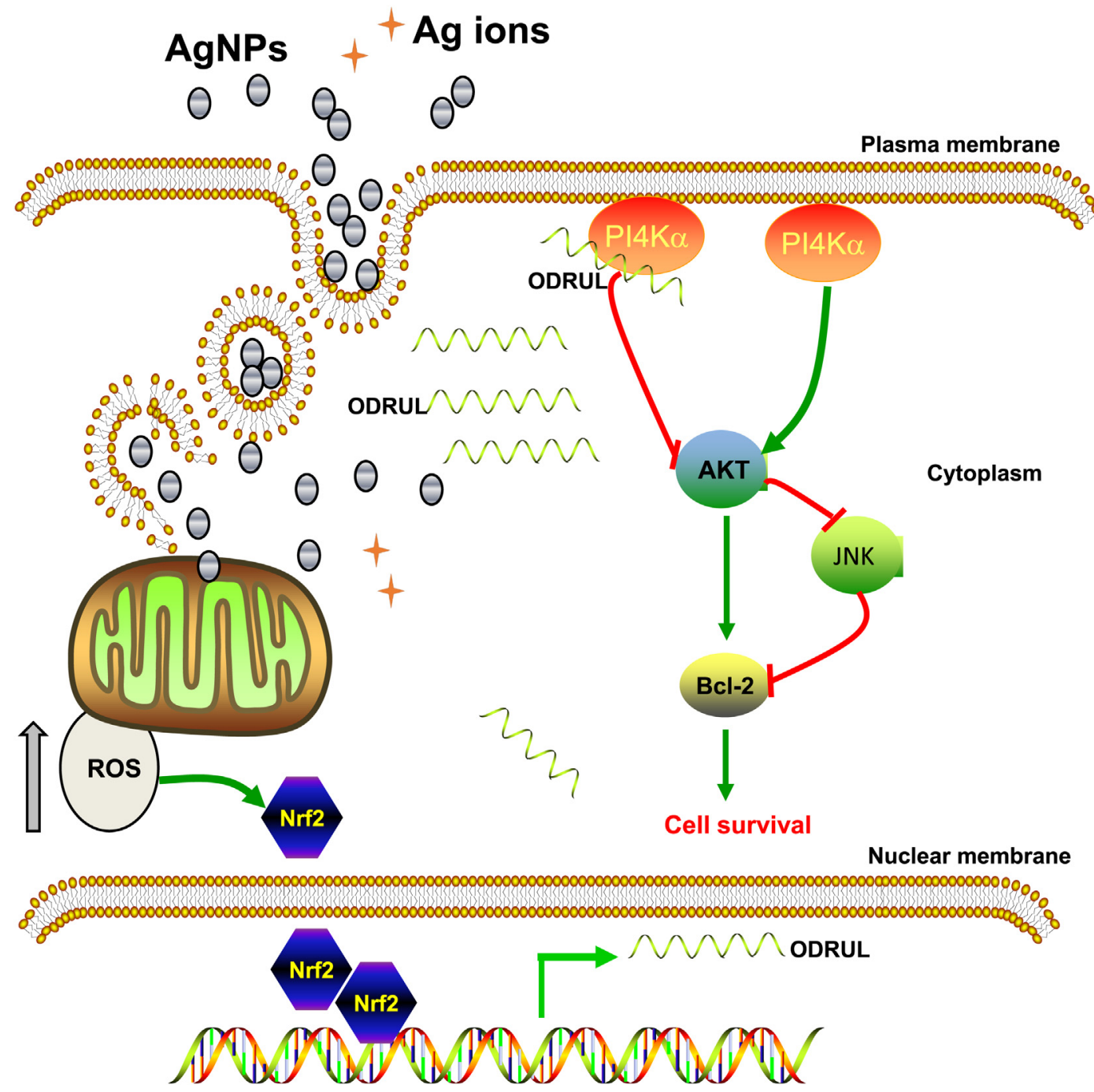

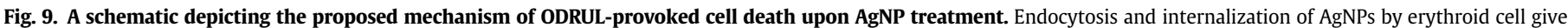

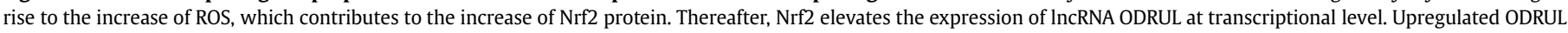

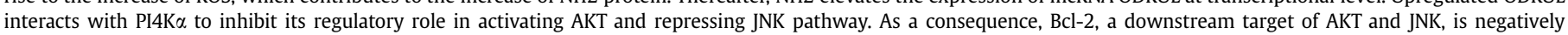
regulated, leading to enhanced cell death.

[61], and JNK in return inhibits the pro-survival function of Bcl-2 [69]. To this end, the induction of ODRUL by AgNPs would also enhance the inhibitory effect of JNK on Bcl-2. Taken together, downstream of ODRUL/PI4K $\alpha$ complex, AKT and JNK converged on Bcl-2 to regulate cell death of K562 cells challenged by AgNPs. However, the detailed regulation between ODRUL/PI4K $\alpha$ complex and AKT/JNK-Bcl-2 needs further investigation.

$\mathrm{Bcl}-2$ is a well-known anti-apoptotic protein, and its upregulation mostly contributes to the cytoprotective effect in many cell types including erythroid cells $[70,71]$. Bcl-2 exerts its antiapoptotic function through sequestering the pro-apoptotic members within the Bcl-2 family, such as BID, BIM and Bax, to avoid their oligomerization and subsequent initiation of cell death $[72,73]$. Therefore, insufficient Bcl-2 induction under stress conditions would compromise the cellular capability against the initiation of apoptosis program, leading to elevated cell death $[74,75]$. Our current results showed that ODRUL contributed to enhanced cell death by negatively regulating the Bcl-2 level under AgNP-induced stress, highlighting the importance of ODRUL's regulation on Bcl-2 by undermining its pro-apoptotic function. Nonetheless, ODRUL may not be the single regulator of the AgNP toxicity, and further studies are needed to shed more light on the complex network.

\section{Conclusion}

IncRNA ODRUL was recognized to be a novel stress regulator in enhancing AgNP-induced cytotoxicity. As illustrated in Fig. 9, the increase of ODRUL expression was attributed to the regulation of Nrf2 induced by oxidative stress. To modulate cell fate, ODRUL interacted with PI4K $\alpha$ to inhibit the pro-survival function of $\mathrm{Bcl}-2$ by impeding the activation on PI4K $\alpha$-AKT-Bcl-2 signaling and enhancing the inhibition of JNK on Bcl-2 through PI4K $\alpha$-AKT-JNK signaling. Thus, AgNP-induced cell death in erythroid cells was accounted for (at least partially) by ODRUL-conducted inhibition on PI4K $\alpha$ and its downstream pro-survival signaling. Our study would offer more insights into the molecular bases underlying AgNPinduced toxicity in erythroid cells.

\section{Competing interests}

There is no potential conflict of interests to disclose. 


\section{Acknowledgments}

This work was supported under grants from the National Natural Science Foundation of China (grant number: 21507154, 21407172, 21425731, 21637004, 81373039), the national "973" program (grant number: 2014CB932000), and the Strategic Priority Research Program of the Chinese Academy of Sciences (Grant No. XDB14000000). We thank the laboratory members for reagents and assistance with experiments.

\section{Appendix A. Supplementary data}

Supplementary data related to this article can be found at http:// dx.doi.org/10.1016/j.biomaterials.2017.03.027.

\section{References}

[1] J. Wolfram, M. Zhu, Y. Yang, J. Shen, E. Gentile, D. Paolino, et al., Safety of nanoparticles in medicine, Curr. Drug Targets 16 (2015) 1671-1681.

[2] A. Martirosyan, Y.J. Schneider, Engineered nanomaterials in food: implications for food safety and consumer health, Int. J. Environ. Res. Public Health 11 (2014) 5720-5750.

[3] A. Radomska, J. Leszczyszyn, M.W. Radomski, The nanopharmacology and nanotoxicology of nanomaterials: new opportunities and challenges, Adv. Clin. Exp. Med. Official organ Wroclaw Med. Univ. 25 (2016) 151-162.

[4] X.F. Zhang, Z.G. Liu, W. Shen, S. Gurunathan, Silver nanoparticles: synthesis, characterization, properties, applications, and therapeutic approaches, Int. J. Mol. Sci. 17 (2016).

[5] L. Wei, J. Lu, H. Xu, A. Patel, Z.S. Chen, G. Chen, Silver nanoparticles: synthesis, properties, and therapeutic applications, Drug Discov. Today 20 (2015) $595-601$.

[6] T. Bartlomiejczyk, A. Lankoff, M. Kruszewski, I. Szumiel, Silver nanoparticles allies or adversaries? Ann. Agric. Environ. Med. AAEM 20 (2013) 48-54.

[7] J.J. Antony, P. Sivalingam, B. Chen, Toxicological effects of silver nanoparticles, Environ. Toxicol. Pharmacol. 40 (2015) 729-732.

[8] D. McShan, P.C. Ray, H. Yu, Molecular toxicity mechanism of nanosilver, J. food drug Anal. 22 (2014) 116-127.

[9] G. St Laurent, C. Wahlestedt, P. Kapranov, The landscape of long noncoding rna classification, Trends Genet. TIG 31 (2015) 239-251.

[10] X. Guo, L. Gao, Y. Wang, D.K. Chiu, T. Wang, Y. Deng, Advances in long noncoding RNAs: identification, structure prediction and function annotation, Brief. Funct. Genomics 15 (2016) 38-46.

[11] S. Djebali, C.A. Davis, A. Merkel, A. Dobin, T. Lassmann, A. Mortazavi, et al., Landscape of transcription in human cells, Nature 489 (2012) 101-108.

[12] T.E. Audas, S. Lee, Stressing out over long noncoding RNA, Biochim. Biophys. acta 1859 (2016) 184-191.

[13] S.U. Schmitz, P. Grote, B.G. Herrmann, Mechanisms of long noncoding RNA function in development and disease, Cell. Mol. Life Sci. CMLS 73 (2016) 2491-2509.

[14] Z.W. Zou, C. Ma, L. Medoro, L. Chen, B. Wang, R. Gupta, et al., LncRNA ANRIL is up-regulated in nasopharyngeal carcinoma and promotes the cancer progression via increasing proliferation, reprograming cell glucose metabolism and inducing side-population stem-like cancer cells, Oncotarget 7 (2016) $61741-61754$

[15] J.H. Yoon, K. Abdelmohsen, M. Gorospe, Posttranscriptional gene regulation by long noncoding RNA, J. Mol. Biol. 425 (2013) 3723-3730.

[16] A.S. Bayoumi, A. Sayed, Z. Broskova, J.P. Teoh, J. Wilson, H. Su, et al., Crosstalk between long noncoding RNAs and microRNAs in health and disease, Int. J. Mol. Sci. 17 (2016) 356.

[17] C. Davidovich, T.R. Cech, The recruitment of chromatin modifiers by long noncoding RNAs: lessons from PRC2, Rna 21 (2015) 2007-2022.

[18] D. Shang, H. Yang, Y. Xu, Q. Yao, W. Zhou, X. Shi, et al., A global view of network of IncRNAs and their binding proteins, Mol. Biosyst. 11 (2015) 656-663.

[19] K. Takahashi, I. Yan, H. Haga, T. Patel, Long noncoding RNA in liver diseases, Hepatology 60 (2014) 744-753.

[20] S. Shi, Q. Peng, X. Shao, J. Xie, S. Lin, T. Zhang, et al., Self-assembled tetrahedral DNA nanostructures promote adipose-derived stem cell migration via lncRNA XLOC 010623 and RHOA/ROCK2 signal pathway, ACS Appl. Mater. Interfaces 8 (2016) 19353-19363.

[21] Q. Wu, X. Zhou, X. Han, Y. Zhuo, S. Zhu, Y. Zhao, et al., Genome-wide identification and functional analysis of long noncoding RNAs involved in the response to graphene oxide, Biomaterials 102 (2016) 277-291.

[22] C. Bussy, L. Methven, K. Kostarelos, Hemotoxicity of carbon nanotubes, Adv. Drug Deliv. Rev. 65 (2013) 2127-2134.

[23] R. Landsiedel, E. Fabian, L. Ma-Hock, B. van Ravenzwaay, W. Wohlleben, K. Wiench, et al., Toxico-/biokinetics of nanomaterials, Arch. Toxicol. 86 (2012) 1021-1060.

[24] R. Golub, A. Cumano, Embryonic hematopoiesis, Blood Cells Mol. Dis. 51 (2013) 226-231.
[25] Z. Wang, S. Liu, J. Ma, G. Qu, X. Wang, S. Yu, et al., Silver nanoparticles induced RNA polymerase-silver binding and RNA transcription inhibition in erythroid progenitor cells, ACS Nano 7 (2013) 4171-4186.

[26] Y. Qian, J. Zhang, Q. Hu, M. Xu, Y. Chen, G. Hu, et al., Silver nanoparticleinduced hemoglobin decrease involves alteration of histone 3 methylation status, Biomaterials 70 (2015) 12-22.

[27] M. Xu, J. Zhu, F. Wang, Y. Xiong, Y. Wu, Q. Wang, et al., Improved in vitro and in vivo biocompatibility of graphene oxide through surface modification: poly(acrylic acid)-functionalization is superior to pegylation, ACS Nano 10 (2016) 3267-3281.

[28] M. Gao, Y. Liu, Y. Chen, C. Yin, J.J. Chen, S. Liu, miR-214 protects erythroid cells against oxidative stress by targeting ATF4 and EZH2, Free Radic. Biol. Med. 92 (2016) 39-49.

[29] C.B. Lozzio, B.B. Lozzio, Human chronic myelogenous leukemia cell-line with positive Philadelphia chromosome, Blood 45 (1975) 321-334.

[30] R. Alitalo, Induced differentiation of K562 leukemia cells: a model for studies of gene expression in early megakaryoblasts, Leukemia Res. 14 (1990) $501-514$.

[31] C. Cantu, R. Ierardi, I. Alborelli, C. Fugazza, L. Cassinelli, S. Piconese, et al., Sox6 enhances erythroid differentiation in human erythroid progenitors, Blood 117 (2011) 3669-3679.

[32] F. Wang, J. Yu, G.H. Yang, X.S. Wang, J.W. Zhang, Regulation of erythroid differentiation by miR-376a and its targets, Cell Res. 21 (2011) 1196-1209.

[33] H. Zhao, A. Kalota, S. Jin, A.M. Gewirtz, The c-myb proto-oncogene and microRNA-15a comprise an active autoregulatory feedback loop in human hematopoietic cells, Blood 113 (2009) 505-516.

[34] I.S. Naarmann-de Vries, A. Brendle, T. Bahr-Ivacevic, V. Benes, D.H. Ostareck, A. Ostareck-Lederer, Translational control mediated by hnRNP K links NMHC IIA to erythroid enucleation, J. Cell Sci. 129 (2016) 1141-1154.

35] P. Lunghi, A. Costanzo, M. Levrero, A. Bonati, Treatment with arsenic trioxide (ATO) and MEK1 inhibitor activates the p73-p53AIP1 apoptotic pathway in leukemia cells, Blood 104 (2004) 519-525.

[36] E.K. Schaeffer, R.J. West, S.J. Conine, C.H. Lowrey, Multiple physical stresses induce gamma-globin gene expression and fetal hemoglobin production in erythroid cells, Blood Cells Mol. Dis. 52 (2014) 214-224.

[37] B. Chenais, M. Andriollo, P. Guiraud, R. Belhoussine, P. Jeannesson, Oxidative stress involvement in chemically induced differentiation of K562 cells, Free Radic. Biol. Med. 28 (2000) 18-27.

[38] M.B. Mathews, N. Sonenberg, J.W.B. Hershey, Translational Control in Biology and Medicine: Cold Spring Harbor Laboratory Press, 2007.

[39] Y. Dong, M. Xiong, L. Duan, Z. Liu, T. Niu, Y. Luo, et al., H2AX phosphorylation regulated by p38 is involved in Bim expression and apoptosis in chronic myelogenous leukemia cells induced by imatinib, Apopt. Int. J. Program. Cell Death 19 (2014) 1281-1292.

[40] L. De Franceschi, M. Bertoldi, L. De Falco, S. Santos Franco, L. Ronzoni, F. Turrini, et al., Oxidative stress modulates heme synthesis and induces peroxiredoxin-2 as a novel cytoprotective response in beta-thalassemic erythropoiesis, Haematologica 96 (2011) 1595-1604.

[41] M.R. Campbell, M. Karaca, K.N. Adamski, B.N. Chorley, X. Wang, D.A. Bell, Novel hematopoietic target genes in the NRF2-mediated transcriptional pathway, Oxidative Med. Cell. Longev. (2013) 120305.

[42] Y. Chen, Z. Wang, M. Xu, X. Wang, R. Liu, Q. Liu, et al., Nanosilver incurs an adaptive shunt of energy metabolism mode to glycolysis in tumor and nontumor cells, ACS Nano 8 (2014) 5813-5825.

[43] S. Marin, G.M. Vlasceanu, R.E. Tiplea, I.R. Bucur, M. Lemnaru, M.M. Marin, et al. Applications and toxicity of silver nanoparticles: a recent review, Curr. Top. Med. Chem. 15 (2015) 1596-1604.

[44] I.S. Kim, M. Baek, S.J. Choi, Comparative cytotoxicity of Al2O3, CeO2, $\mathrm{TiO} 2$ and ZnO nanoparticles to human lung cells, J. Nanosci. Nanotechnol. 10 (2010) 3453-3458.

[45] A. Kermanizadeh, G. Pojana, B.K. Gaiser, R. Birkedal, D. Bilanicova, H. Wallin, et al., In vitro assessment of engineered nanomaterials using a hepatocyte cell line: cytotoxicity, pro-inflammatory cytokines and functional markers, Nanotoxicology 7 (2013) 301-313.

[46] E.J. Park, J. Yi, Y. Kim, K. Choi, K. Park, Silver nanoparticles induce cytotoxicity by a Trojan-horse type mechanism, Toxicol. Vitro 24 (2010) 872-878.

[47] C. Beer, R. Foldbjerg, Y. Hayashi, D.S. Sutherland, H. Autrup, Toxicity of silver nanoparticles-nanoparticle or silver ion? Toxicol. Lett. 208 (2012) 286-292.

[48] S. Kim, J.E. Choi, J. Choi, K.H. Chung, K. Park, J. Yi, et al, Oxidative stressdependent toxicity of silver nanoparticles in human hepatoma cells, Toxicol. Vitro 23 (2009) 1076-1084.

[49] Y.H. Lee, F.Y. Cheng, H.W. Chiu, J.C. Tsai, C.Y. Fang, C.W. Chen, et al., Cytotoxicity, oxidative stress, apoptosis and the autophagic effects of silve nanoparticles in mouse embryonic fibroblasts, Biomaterials 35 (2014) $4706-4715$

[50] A.K. Jaiswal, Nrf2 signaling in coordinated activation of antioxidant gene expression, Free Radic. Bio Med. 36 (2004) 1199-1207.

[51] P. Thai, S. Statt, C.H. Chen, E. Liang, C. Campbell, R. Wu, Characterization of a novel long noncoding RNA, SCAL1, induced by cigarette smoke and elevated in lung cancer cell lines, Am. J. Respir. Cell Mol. Biol. 49 (2013) 204-211.

[52] Y. Zhang, J. Xia, Q. Li, Y. Yao, G. Eades, R. Gernapudi, et al., NRF2/long noncoding RNA ROR signaling regulates mammary stem cell expansion and protects against estrogen genotoxicity, J. Biol. Chem. 289 (2014) 31310-31318.

[53] G. Bohmdorfer, A.T. Wierzbicki, Control of chromatin structure by long 
noncoding RNA, Trends Cell Biol. 25 (2015) 623-632.

[54] N. Bojjireddy, J. Botyanszki, G. Hammond, D. Creech, R. Peterson, D.C. Kemp, et al., Pharmacological and genetic targeting of the PI4KA enzyme reveals its important role in maintaining plasma membrane phosphatidylinositol 4phosphate and phosphatidylinositol 4,5-bisphosphate levels, J. Biol. Chem. 289 (2014) 6120-6132.

[55] A.W. Tai, S. Salloum, The Role of the phosphatidylinositol 4-kinase PI4KA in hepatitis c virus-induced host membrane rearrangement, PloS One 6 (2011).

[56] J. Yang, X.S. Liu, K. Bhalla, C.N. Kim, A.M. Ibrado, J.Y. Cai, et al., Prevention of apoptosis by Bcl-2: release of cytochrome c from mitochondria blocked, Science 275 (1997) 1129-1132.

[57] S. Liu, R. Xu, I. Gerin, W.P. Cawthorn, O.A. Macdougald, X.W. Chen, et al., SRA regulates adipogenesis by modulating p38/JNK phosphorylation and stimulating insulin receptor gene expression and downstream signaling, PloS One 9 (2014) e95416.

[58] M. Weiss, C. Plass, C. Gerhauser, Role of lncRNAs in prostate cancer development and progression, Biol. Chem. 395 (2014) 1275-1290.

[59] S. Xu, S. Sui, J. Zhang, N. Bai, Q. Shi, G. Zhang, et al., Downregulation of long noncoding RNA MALAT1 induces epithelial-to-mesenchymal transition via the PI3K-AKT pathway in breast cancer, Int. J. Clin. Exp. Pathol. 8 (2015) 4881-4891.

[60] K.M. Chu, S. Minogue, J.J. Hsuan, M.G. Waugh, Differential effects of the phosphatidylinositol 4-kinases, PI4KIIalpha and PI4KIIIbeta, on Akt activation and apoptosis, Cell Death Dis. 1 (2010) e106.

[61] H.F. Zhao, J. Wang, S.S. Tony To, The phosphatidylinositol 3-kinase/Akt and cJun N-terminal kinase signaling in cancer: alliance or contradiction? (Review), Int. J. Oncol. 47 (2015) 429-436.

[62] C.A. dos Santos, M.M. Seckler, A.P. Ingle, I. Gupta, S. Galdiero, M. Galdiero, et al., Silver nanoparticles: therapeutical uses, toxicity, and safety issues, J. Pharm. Sci. 103 (2014) 1931-1944.

[63] S. Kim, D.Y. Ryu, Silver nanoparticle-induced oxidative stress, genotoxicity and apoptosis in cultured cells and animal tissues, J. Appl. Toxicol. JAT 33 (2013) 78-89.
[64] S.C. Lu, Regulation of glutathione synthesis, Mol. Aspects Med. 30 (2009) $42-59$

[65] K. Takahashi, I.K. Yan, J. Wood, H. Haga, T. Patel, Involvement of extracellular vesicle long noncoding RNA (linc-VLDLR) in tumor cell responses to chemotherapy, Mol. Cancer Res. MCR 12 (2014) 1377-1387.

[66] C. Wang, X. Wu, F. Shen, Y. Li, Y. Zhang, D. Yu, Shlnc-EC6 regulates murine erythroid enucleation by Rac1-PIP5K pathway, Dev. Growth Differ. 57 (2015) 466-473.

[67] N. Bojjireddy, J. Botyanszki, G. Hammond, D. Creech, R. Peterson, D.C. Kemp, et al., Pharmacological and genetic targeting of the PI4KA enzyme reveals its important role in maintaining plasma membrane phosphatidylinositol 4phosphate and phosphatidylinositol 4,5-bisphosphate levels, J. Biol. Chem. 289 (2014) 6120-6132.

[68] P.T. Hawkins, K.E. Anderson, K. Davidson, L.R. Stephens, Signalling through class I PI3Ks in mammalian cells, Biochem. Soc. Trans. 34 (2006) 647-662.

[69] G. Verma, M. Datta, The critical role of JNK in the ER-mitochondrial crosstalk during apoptotic cell death, J. Cell. Physiol. 227 (2012) 1791-1795.

[70] Q. Xiao, Y. Hu, Y. Liu, Z. Wang, H. Geng, L. Hu, et al., BEX1 promotes imatinibinduced apoptosis by binding to and antagonizing BCL-2, PloS One 9 (2014) e91782.

[71] P.N. Kelly, A. Strasser, The role of Bcl-2 and its pro-survival relatives in tumourigenesis and cancer therapy, Cell death Differ. 18 (2011) 1414-1424.

[72] C.J. Gibson, M.S. Davids, $\mathrm{BCl}-2$ antagonism to target the intrinsic mitochondrial pathway of apoptosis, Clin. Cancer Res. Off. J. Am. Assoc. Cancer Res. 21 (2015) 5021-5029.

[73] B. Leibowitz, J. Yu, Mitochondrial signaling in cell death via the Bcl-2 family, Cancer Biol. Ther. 9 (2010) 417-422.

[74] F. Llambi, D.R. Green, Apoptosis and oncogenesis: give and take in the BCL-2 family, Curr. Opin. Genet. Dev. 21 (2011) 12-20.

[75] M. Kvansakul, M.G. Hinds, The Bcl-2 family: structures, interactions and targets for drug discovery, Apoptosis Int. J. Program. Cell Death 20 (2015) 136-150. 